\title{
Nsr1, a nitrogen source-regulated microprotein, confers an alternative mechanism of G1/S transcriptional activation in budding yeast
}

Sylvain Tollis ${ }^{1,{ }^{*},{ }^{\dagger}}$, Jaspal Singh ${ }^{2,+}$, Yogitha Thattikota ${ }^{1, \ddagger}$, Xiaojing Tang ${ }^{2}$, Susan Moore ${ }^{1}$, Deborah Blake $^{1}$, Jasmin Coulombe-Huntington ${ }^{1}$, Eric Bonneil ${ }^{1}$, Catherine A. Royer ${ }^{3}$, Pierre Thibault ${ }^{1}$ and Mike Tyers ${ }^{1, *}$

${ }^{1}$ Institute for Research in Immunology and Cancer, University of Montréal, Montréal, Quebec, Canada

${ }^{2}$ Lunenfeld-Tanenbaum Research Institute, Mount Sinai Hospital, Toronto, Ontario, Canada

${ }^{3}$ Department of Biological Sciences, Rensselaer Polytechnic Institute, Troy, NY, USA

${ }^{\dagger}$ equal contribution to this work

‡ Present address: Montreal Neurological Institute, McGill University, Montréal, Quebec, Canada; Department of Neurology and Neurosurgery, McGill University, Montreal, Quebec, Canada

* To whom correspondence should be addressed: sylvain.tollis@umontreal.ca; md.tyers@umontreal.ca

keywords: Saccharomyces cerevisiae, genetic screen, G1/S transcription, Start, transcription factor, nutrient limitation, microprotein, evolution, quantitative microscopy

running title: A microprotein activates $\mathrm{G} 1 / \mathrm{S}$ transcription under nitrogen limitation 


\begin{abstract}
Commitment to cell division at the end of G1 phase, termed Start in the budding yeast Saccharomyces cerevisiae, is strongly influenced by nutrient availability. To identify new dominant activators of Start that might operate under different nutrient conditions, we screened a genome-wide ORF overexpression library for genes that bypass a Start arrest caused by absence of the $\mathrm{G} 1$ cyclin $\mathrm{Cln} 3$ and the transcriptional activator Bck2. We recovered a hypothetical gene YLR053c, renamed NSR1 for Nitrogen-responsive Start Regulator 1, which encodes a poorly characterized 108 amino acid microprotein. Endogenous Nsr1 was nuclear-localized, restricted to poor nitrogen conditions, induced upon mTORC1 inhibition, and cell cycle-regulated with a peak at Start. NSR1 interacted genetically with SWI4 and SWI6, which encode the master G1/S transcription factor complex SBF. Correspondingly, Nsr1 physically interacted with Swi4 and Swi6 and was localized to G1/S promoter DNA. Nsr1 exhibited inherent transactivation activity and fusion of Nsr1 to the SBF inhibitor Whi5 was sufficient to suppress other Start defects. Nsr1 appears to be a recently evolved microprotein that rewires the $\mathrm{G} 1 / \mathrm{S}$ transcriptional machinery under poor nutrient conditions.
\end{abstract}

\title{
Author Summary
}

Unicellular microorganisms must adapt to ever-changing nutrient conditions and hence must adjust cell growth and proliferation to maximize fitness. In the budding yeast Saccharomyces cerevisiae, commitment to cell division, termed Start, is heavily influenced by nutrient availability. The mechanisms of Start activation under conditions of nutrient limitation are less well characterized than under nutrient excess. To identify potential new Start regulators specific to poor nutrient environments, we screened for genes able to bypass a genetic Start arrest caused by loss of the $\mathrm{G} 1$ cyclin $\mathrm{Cln} 3$ and the transcriptional activator Bck2. This screen uncovered YLR053c, which we renamed NSR1 for Nitrogen-responsive Start Regulator. Sequence analysis across yeast species indicated that Nsr1 is a recently-evolved microprotein. We showed that NSR1 is nutrient- and cell cycle-regulated, and directly binds the main G1/S transcription factor complex SBF. We demonstrated that Nsr1 has an intrinsic trans-activation activity and provided genetic evidence to suggest that Nsr1 can bypass the requirement for normal Cln3-dependent 
activation of SBF. These results uncover a new mechanism of Start activation and demonstrate how microproteins can rapidly emerge to rewire fundamental cellular processes.

\section{Introduction}

All organisms have evolved adaptive regulatory mechanisms to optimize fitness in the face of ever-changing environmental conditions. This ability to adapt is particularly important for unicellular organisms which lack the capacity to establish the internal homeostatic environment of metazoan species. In the budding yeast Saccharomyces cerevisiae, different carbon and nitrogen sources can dramatically affect the rates of cell growth and division, as well as developmental programs (1). Yeast cells commit to division at the end of G1 phase, an event referred to as Start $(2,3)$. In order to pass Start, cells must grow to a characteristic critical size that constrains the overall size distribution of an asynchronous population of cells. The size threshold dynamically adjusts to changing nutrient availability thereby optimizing competitive fitness (3). How nutrient conditions modulate the growth and division machinery at the molecular level is still largely unknown.

Start initiates a complex G1/S transcriptional program of $\sim 200$ genes that encode proteins necessary for bud emergence, DNA replication, spindle body duplication and other processes. This program is controlled by two transcription factor complexes, SBF (Swi4/6 Cell Cycle Box binding factor) and MBF (Mlul Cell Cycle Box binding factor), each comprised of related DNAbinding proteins, Swi4 and Mbp1 respectively, coupled to a common regulatory subunit Swi6 (4, 5). Individually Swi4 and Mbp1 are not essential but a double swi4 $\Delta$ mbp1 1 mutant is inviable (6), consistent with the significant overlap between SBF and MBF binding sites in G1/S promoters (7-10). In pre-Start cells that have not achieved the critical cell size, SBF is inhibited by the Whi5 transcriptional repressor(11-13). At Start, the G1 cyclin (Cln)-Cdc28 protein kinases phosphorylate both SBF and Whi5 to disrupt the SBF-Whi5 interaction and trigger Whi5 nuclear export (12-14). The upstream G1 cyclin Cln3 is thought to initiate a positive feedback loop in which SBF-dependent expression of CLN1/2 further amplifies (Cln)-Cdc28 activity and thus SBF activation $(15,16)$. The expression of $\mathrm{Cln} 3$ itself does not rely on the SBF-dependent positive feedback (17). Although CLN3 was isolated as a potent dose-dependent activator of Start(18), the 
size-dependent mechanism whereby $\mathrm{Cln3-Cdc28}$ initiates the SBF positive feedback loop remains uncertain $(19,20)$. CLN3 is essential only in the absence of other parallel activators of Start, most notably $B C K 2$, which encodes a general transcriptional activator $(21,22)$.

Connections between the main yeast nutrient signalling conduits, the cell size threshold and Start have been established. Activation of the protein kinase A (PKA) pathway by glucose represses CLN1 and other G1/S transcripts, which may increase the cell size threshold in rich nutrients (23, 24). The TOR signalling network, which controls many aspects of cell growth including the rate of ribosome biogenesis, has been linked to the size threshold $(11,25-27)$. The TORC1 complex phosphorylates and activates the effector kinase Sch9 and the master transcription factor Sfp1 to activate ribosomal protein (RP) and ribosome biogenesis (Ribi) genes $(25,26,28)$. Deletion of either SFP1 or SCH9 abrogates the carbon source-dependent control of cell size (25). The Rim15 kinase, which is active under respiratory growth conditions in poor carbon sources, may suppress the Cdc55 phosphatase that dephosphorylates Whi5, and thereby contribute to Whi5 inactivation even when Cln3 activity is low (29). Poor nutrient conditions also increase the expression of the G1/S transcription factors and thereby activate Start at a smaller cell size (30). Notably though, a $\ln 3 \Delta$ bck2 $\Delta$ whi5 $\Delta$ triple mutant is completely viable and still responds to nutrient cues, suggesting that nutrient regulation of Start may be partly independent of the CIn3Bck2-Whi5-SBF axis $(12,25)$.

To identify nutrient-dependent activators of Start that might act in parallel to the central Cln3Bck2-Whi5 pathway, we screened for dosage suppressors of the lethal $\ln 3 \Delta b c k 2 \Delta$ Start arrest phenotype $(12,13,31,32)$. This screen identified $Y L R 053 c$, a poorly characterized hypothetical gene that encodes a recently evolved 108 amino acid microprotein, which we renamed NSR1 for Nitrogen-responsive Start Regulator 1 . Nsr1 protein was only observed in poor nitrogen conditions and was cell cycle-regulated with peak nuclear localization at Start. Nsr1 genetically and physically interacted with SBF, and caused a small size phenotype when overexpressed in wild type cells. Nsr1 exhibited intrinsic trans-activation activity and direct fusion of Nsr1 to Whi5 was sufficient to reduce cell size in rich carbon sources and rescue the $\ln 3 \Delta b c k 2 \Delta$ lethality. These results demonstrate that the recently evolved Nsr1 microprotein allows cells to adapt to 
poor nutrient conditions by rewiring the Start transcriptional machinery.

\section{$\underline{\text { Results }}$}

A genome-wide screen identifies overexpression of $Y L R 053 c$ as a rescue of $\ln 3 \Delta$ bck2 $\Delta$ lethality We constructed a $\ln 3 \Delta$ bck2 $\triangle$ whi5::GAL1-WHI5 strain that is viable in glucose medium but not in galactose due to conditional WHI5 expression $(12,13)$. We used the SGA methodology to cross this query strain to an array of 5280 GAL1-GST-ORF strains (33-35) and assessed the growth of the resulting array in galactose (Figure 1A, B). Three replicates of the screen identified 12 genes that reproducibly rescued the $c \ln 3 \Delta b c k 2 \Delta$ lethal Start arrest (Table 1$)$. These genes included the G1 cyclins CLN1 and CLN3 but not other known Start activators such as CLN2, BCK2, SWI4 and SWI6, possibly due to the WHI5 overexpression and/or overexpression toxicity of particular genes. We recovered 10 genes not known to be Start regulators such as YEA4, which encodes a uridine diphosphate-N-acetylglucosamine transporter. Notably, the short hypothetical ORF YLR053c restored $c \ln 3 \Delta b c k 2 \Delta$ growth to the same extent as CLN3, as assessed by direct transformation of the query strain with GAL1-YLR053c and GAL1-CLN3 constructs (Figure 1C).

YLR053c encodes a 108 residue microprotein that is only poorly characterized. Microproteins are often encoded by newly evolved proto-genes that are thought to form a genetic reservoir that fuels adaptive evolution (36). To gain insight into the YLR053c locus evolution, we aligned the YIr053c protein sequence from S. cerevisiae with predicted orthologs from other yeast species (Figure 1D, E). The YLR053c locus appears to have evolved relatively rapidly within the Saccharomyces sensu stricto group, with a dN/dS ratio in the $98^{\text {th }}, 79^{\text {th }}$ and $90^{\text {th }}$ percentile in $S$. mikatae, S. bayanus and S. castellii, respectively as compared with S. cerevisiae (Figure S1A). In comparison, the evolution of other core Start regulators was closer to the genome median, with $\mathrm{dN} / \mathrm{dS}$ ratios in the $74^{\text {th }}, 77^{\text {th }}$ and $58^{\text {th }}$ percentile for WHI5, $69^{\text {th }}, 75^{\text {th }}$ and $31^{\text {st }}$ percentile for SWI4, and $82^{\text {nd }}, 51^{\text {st }}$ and $43^{\text {rd }}$ percentile for SWI6. A 17 amino acid sequence at the Ylr053c C-terminal region was conserved even in more distant yeasts such as $K$. waltii (Figure 1E). From this point forward, we refer to YLR053c as NSR1 for reasons described below.

\section{Nsr1 is induced by rapamycin and nitrogen limitation}


To understand the function of Nsr1 we first sought to characterize its endogenous expression. We performed scanning Number and Brightness (sN\&B) confocal microscopy to localize and quantify Nsr1 fused with GFPmut3 at the subcellular scale in live wild-type (WT) cells under a range of conditions $(30,37)$. GFPmut3, a monomeric fast-folding GFP mutant (38), will be referred to here as GFP for brevity. Nsr1-GFP was not detected in cells grown on either SC+2\% glucose or $\mathrm{SC}+2 \%$ raffinose medium (Figure $2 \mathrm{~A}$ ), consistent with previous analysis of YLR053/NSR1 mRNA levels (39). In contrast, Nsr1-GFP was readily detected in the nucleus of cells grown overnight to mid log-phase in nitrogen-limited YNB pro glu medium (Figure 2A). This result was consistent with genome-wide transcriptome analysis under various nutrient conditions (40). Inhibition of TORC1 with 100nM rapamycin rapidly and transiently induced Nsr1-GFP expression and nuclear localization in rich $\mathrm{SC}+2 \%$ glucose medium (Figure $2 \mathrm{~A}$; Figure $\mathrm{S} 1 \mathrm{~B}$ ). These expression patterns were confirmed with an independent Nsr1-wtGFP fusion protein (Figure S1C). Hyperosmotic stress, oxidative stress and DNA damage did not induce Nsr1 expression in $\mathrm{SC}+2 \%$ glucose medium (Figure S1D). Immunoblot analysis of strains bearing a MYC epitope-tagged version of Nsr1 in different carbon and nitrogen sources, as well as in rapamycin-treated and saturated cultures, confirmed the specific expression of Nsr1 only under conditions of nitrogen limitation or TORC1 inhibition (Figure 2B). In accord with its genetic role at Start and expression pattern, we therefore renamed the gene NSR1 for Nitrogen-responsive Start Regulator.

\section{Nsr1 abundance peaks at the G1/S transition}

We quantified Nsr1 level in asynchronous populations of live cells grown in nitrogen-limited YNB pro glu medium with our custom sN\&B analysis software (30). Single cell-averaged Nsr1 levels were between 5 and $20 \mathrm{nM}$. Higher levels were observed in cells close to the typical critical size at the end of G1 phase, where the predominant nuclear Nsr1-GFP signal corresponded to 60-80 nM (Figure 2C). These Nsr1 nuclear levels at Start were comparable to Swi4 (50-100 nM), Whi5 (100-120 nM) and Swi6 (130-170 nM) levels determined previously by the same method (30). We further confirmed Nsr1 expression and nuclear localization in large unbudded and small budded cells in images acquired by standard confocal microscopy (Figure 2D). The cell cycle-regulated expression pattern of Nsr1 protein suggested that it plays a role at Start, consistent with the 
suppression of the $\ln 3 \Delta b c k 2 \Delta$ arrest by $N S R 1$ overexpression.

\section{Overexpressed NSR1 genetically interacts with SBF}

To investigate the molecular mechanism by which Nsr1 promotes Start, we examined genetic interactions of NSR1 with the main known Start regulators. Overexpression of NSR1 from the GAL1 promoter, either integrated at the NSR1 locus or from a multi-copy plasmid, caused a pronounced small size phenotype, in agreement with its putative role as a Start activator (Figure $3 A, B)$. To interrogate the genetic requirements for this size phenotype, we transformed deletion mutants of known Start regulators with a GAL1-NSR1 multi-copy plasmid and examined cell size epistasis. Strikingly, NSR1 overexpression almost entirely rescued the large size phenotype of a $\operatorname{cln} 3 \Delta$ mutant and partially rescued the large size of a $b c k 2 \Delta$ mutant (Figure 3B). A whi5 $\Delta$ mutant was epistatic to NSR1 overexpression while a $n s r 1 \Delta$ deletion did not exacerbate the larger size caused by WHI5 overexpression and only modestly increased the size of a whi5 $\Delta$ mutant (Figure 3C). Notably, the small size caused by NSR1 overexpression was abrogated in swi6 $\Delta$ and swi4 $\Delta$ mutant strains (Figure 3D). This requirement for SWI4 function was further demonstrated with a temperature-sensitive swi4 strain grown at the semi-permissive temperature of $30^{\circ} \mathrm{C}$ (Figure $3 \mathrm{E}$ ). In contrast to its overexpression, deletion of NSR1 did not detectably affect overall growth rate or cell size in any growth media tested (Figure S2A-D). Moreover, in competitive growth experiments, $n s r 1 \Delta$ and WT cells had indistinguishable fitness (Figure S2E). Taken together, these results suggested that overexpression of Nsr1 promotes small cell size upstream of Whi5inhibited SBF independently of Cln3 and Bck2.

\section{Endogenous Nsr1 interacts with SBF in vivo and in vitro}

We next sought to identify Nsr1 protein interactors in physiological conditions. We performed immunoaffinity purification on lysates from an endogenously tagged Nsr1 $1^{13 M Y C}$ strain grown in nitrogen-limited YNB-pro-glu medium. Analysis of the samples by mass spectrometry using stringent thresholds (Methods) identified multiple peptides (Table S3) in both Nsr1 ${ }^{13 \mathrm{MYC}}$ cells and untagged wild-type strains, from which individual proteins were identified with high confidence ( $>2$ unique peptides, false discovery rate $<1 \%$, Table S4). Comparison between Nsr1 $1^{13 M Y C}$ and 
untagged negative control strains identified 47 proteins in the Nsr1 $1^{13 M Y C}$ sample specifically (Table S2). Nsr1 was represented by 7 peptides (48\% coverage), Swi4 by 5 peptides, and Swi6 by 5 peptides (Figure S2F, Table S2). This unbiased analysis suggested that Nsr1 interacts with SBF in vivo. To confirm this result, we performed co-immunoprecipitation experiments on extracts of rapamycin-treated cells expressing MYC-tagged NSR1 or WHI5 alleles from their endogenous promoters or from an untagged control strain (Figure 4A). Nsr1 ${ }^{\mathrm{MYC}}$, Whi5 ${ }^{\mathrm{MYC}}$, Swi4 and Swi6 were each immunoprecipated and then blotted with antibodies against each protein. The specific association of Nsr1 ${ }^{\text {MYC }}$ with both Swi4 and Swi6 resembled that of Whi5 ${ }^{\text {MYC }}$ suggesting that Nsr1 may directly interact with SBF under physiological conditions.

To determine if the interactions between Nsr1 and SBF were indeed direct, we carried out in vitro

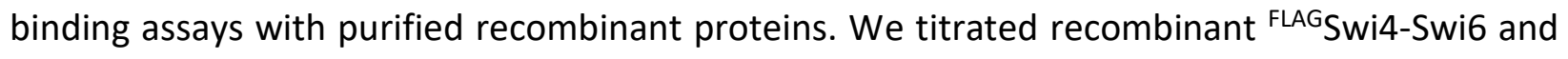
FLAGMbp1-Swi6 complexes produced in baculovirus-infected insect cells (12) against recombinant

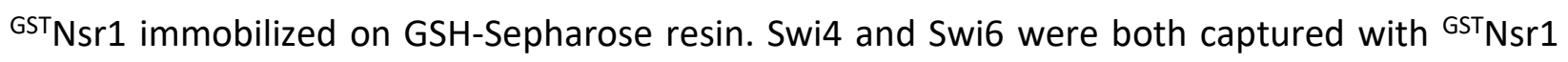
across the titration series whereas control GSH-Sepharose resin did not bind either protein

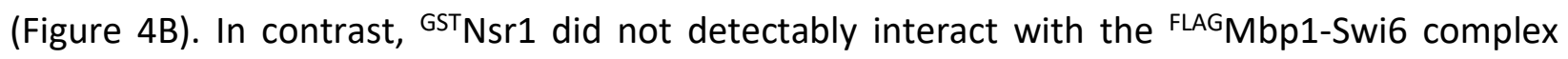
under the conditions tested, suggesting that specificity for Nsr1 is determined by the DNA binding subunit and not the common Swi6 subunit. These results demonstrated that endogenous Nsr1 interacts directly and specifically with the Swi4-Swi6 complex, and that no additional factors are needed for this interaction to occur.

\section{Nsr1 binds to SBF-regulated promoters in vivo}

We next assessed the presence of Nsr1 ${ }^{13 M Y C}$ at the SBF-regulated promoters of CLN2 and PCL1 by chromatin immunoprecipitation (ChIP). For both genes, we specifically detected SCB-containing promoter sequences by PCR in cross-linked MYC immune complexes purified from cells that expressed Nsr1 $1^{13 M Y C}$ from the endogenous NSR1 locus (Figure 4C). The enrichment of PCL1 and CLN2 sequences only upon rapamycin-induced Nsr1 expression further demonstrated that Nsr1 specifically binds SBF-regulated G1/S promoter DNA (Figure 4C).

Nsr1 binding to chromatin should reduce the protein mobility in the nucleus. To test this 
hypothesis, we assessed the dynamics of Nsr1-GFP in cells grown in nitrogen-limited media using Raster Image Correlation Spectroscopy (RICS). RICS exploits the hidden time structure of imaging scans, in which adjacent pixels are imaged a few microseconds apart, to quantify the diffusional properties of fluorescent molecules (41-43). Intensity correlations between pixels shifted along the direction of scanning (horizontal correlations), and along the orthogonal direction (vertical correlations), are averaged over multiple scans. Horizontal and vertical correlations that decay with increasing pixel shift are characteristic of the dynamical properties on 10-100 $\mu$ s and 5-50 ms timescales respectively. We found that the vertical RICS correlations of nuclear Nsr1-GFP signal decreased on a slower timescale than either free nuclear GFP or cytosolic Nsr1-GFP signal (Figure 4D). Fitted diffusion coefficients were correspondingly lower for nuclear Nsr1 compared to free nuclear GFP or cytosolic Nsr1, and were closer to that of DNA-bound Swi6-GFP (Figure 4D). This result indicated that Nsr1 associates with a slowly-moving nuclear component, most likely chromatin.

The size epistasis between whi5 $\triangle$ and GAL1-NSR1 prompted us to ask whether Nsr1 might reduce the association Whi5 with SBF and/or chromatin. However, ChIP analysis of Whi5 ${ }^{\mathrm{HA}}$ at the CLN2 and PCL1 promoters revealed that Whi $5^{\mathrm{HA}}$-promoter interactions were not reduced in the presence of overexpressed Nsr1 (Figure S3A). In addition, GAL1-NSR1 cells had wild-type levels of Whi5 as determined by SN\&B quantification (Figure S3B) and Nsr1 did not alter Whi5 ${ }^{\mathrm{HA}}$ association with Swi4 or Swi6 in co-immunoprecipitation experiments (Figure S3C). Nsr1 and Whi5 also did not compete for SBF binding in in vitro binding assays with recombinant proteins (Figure S3D). Together, these results obtained using different in vivo, in vitro, biochemical and imaging-based approaches suggested that Nsr1 binds SBF at G1/S promoters in vivo, but that this binding does not alter Whi5 interactions with SBF or promoter DNA.

\section{Nsr1 confers transcriptional activity that can rescue G1/S-transcription deficient mutants}

We next hypothesized that Nsr1 might directly contribute to G1/S transcriptional activation. To test this hypothesis, we expressed a Nsr1-Gal4 DNA binding domain fusion protein (GAL4-DBDNSR1) in cells where the HIS3 auxotrophic marker is under the control of the GAL1 promoter. We 
used the GAL4-DBD alone and GAL4-DBD fused to an irrelevant human gene (UBE2G2) that potently transactivates as negative and positive controls, respectively. Full length NSR1 but not its conserved C-terminus was able to activate transcription of the HIS3 reporter and thereby allow cell growth in medium lacking histidine (Figure 5A).

Given the apparent transactivation activity of Nsr1, we then tested whether Nsr1 overexpression could suppress the growth defects of mutants in which $\mathrm{G} 1 / \mathrm{S}$ transcription was impaired. We first tested a mbp1 $\Delta$ swi4-ts double mutant (44). The growth of GAL1-NSR1 mbp1 $\Delta$ swi4-ts cells was improved with respect to the $m b p 1 \Delta$ swi4-ts control at a semi-permissive temperature of $30^{\circ}$ in galactose medium, but not in other media or at the permissive temperature (Figure 5B; Figure

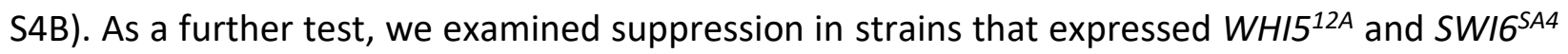
alleles in which all Cdc28 consensus sites are mutated, a combination that abrogates Cln-Cdc28 mediated relief of SBF inhibition by Whi5 $(12,14)$. Overexpression of NSR1 also partially rescued the growth defect of this strain (Figure 5C). These results suggested that Nsr1 provides an alternative mechanism of Start activation by augmenting $\mathrm{G} 1 / \mathrm{S}$ transcription irrespective of Whi5 inhibition.

\section{Nsr1 contributes to bypass Whi5 inhibition of SBF}

To test whether physiological levels of Nsr1 targeted to SBF are sufficient to promote Start activation, we constructed a strain expressing a Whi5-Nsr1-GFP fusion protein from the endogenous WHI5 promoter. In rich nitrogen medium, i.e., when endogenous Nsr1 is not expressed, the chimeric protein was expressed and had the expected molecular mass (Figure S5A). The Whi5-Nsr1-GFP chimera retained the localization pattern of endogenous Whi5, with about $30-35 \%$ of pre-Start cells showing a prominent nuclear signal (Figures 6A; Figure S5B). Cells expressing Whi5-Nsr1-GFP were almost as small as whi5 $\Delta$ cells (Figure 6B), and as small as cells that expressed GAL1-NSR1 in galactose medium (Figure 6C). The small size phenotype conferred by the Whi5-Nsr1-GFP expression was not due to the presence of the GFP tag since size distributions of strains expressing untagged versus GFP-tagged Whi5 were indistinguishable (Figure S5C). Moreover, cells expressing the chimeric protein grew at the same rate as WT and whi5 $\Delta$ strains (Figure S5D). 
As a reduction of Whi5 dosage in the Whi5-Nsr1-GFP fusion context could in principle explain the small size of this strain, we used SN\&B to compare the nuclear concentrations of Whi5 in the WT and the Nsr1-fusion contexts. Whi5 levels in WT cells were 110-130 nM, consistent with those determined previously (30). The Whi5-Nsr1-GFP chimera was present at a slightly lower concentration, 80-100nM (Figure 6A), close to endogenous Nsr1 nuclear levels in nitrogenlimited media (60-80nM, see Figure $2 \mathrm{C})$. This slight decrease in Whi5 abundance was unlikely to explain the small size of cells expressing Whi5-Nsr1-GFP since cell size is not strongly sensitive to WHI5 gene dosage (45). We confirmed that hemizygous WHI5/whi5A diploid cells were only marginally smaller than WT diploid cells (Figure S5E) and WHI5 overexpression only causes a 20$30 \%$ increase in mode size (Figure 3C), in agreement with previous results (45). Consistently, our previously published Start model (30) also predicted that downregulating Whi5 levels from $120 \mathrm{nM}$ to $85 \mathrm{nM}$ should not affect the critical size at Start (Figure S5F).

Finally, we predicted that the Whi5-Nsr1 fusion should be sufficient to rescue the lethal Start arrest of a $\operatorname{cln} 3 \Delta b c k 2 \Delta$ strain. We crossed a cln3 $\Delta$ strain bearing the integrated WHI5-NSR1-GFP allele to a $b c k 2 \Delta$ strain and analyzed growth of dissected tetrads on selective media to identify spore genotypes (Figure 6D). We recovered many viable cln3 $\Delta$ bck2 $\Delta$ WHI5-NSR1-GFP triple mutant spore clones but did not recover any viable cln3 $\Delta$ bck2 $\Delta$ WHI5 double mutant clones (Figure 6D). As expected, no viable $\ln 3 \Delta b c k 2 \Delta$ spore clones were obtained from a control cross of a $c \ln 3 \Delta$ WHI5-GFP and a $b c k 2 \Delta$ strain (Figure 6D). These results supported the model in which Nsr1 bypasses Whi5 inhibition by directly conferring transactivation activity to the inhibited SBF complex.

\section{Discussion}

On the premise that additional genes may activate Start under suboptimal nutrient conditions, we screened for genes that can circumvent the Start arrest caused by loss of CLN3 and BCK2 function. We discovered that NSR1 overexpression efficiently bypasses the lethality of a cln3 $\Delta$ bck2 $\Delta$ strain and activates Start in wild type cells; that Nsr1 associates with SBF at G1/S promoter DNA; that NSR1 overexpression can genetically suppress defects in SBF function; and that Nsr1 is itself a transcriptional activator. Our data suggest a model whereby nitrogen 
depletion or TORC1 inhibition promote NSR1 expression, likely via the TORC1-regulated transcription factor $\operatorname{Gln} 3(46,47)$. Subsequent Nsr1 binding to SBF yields a direct recruitment of the transcriptional machinery such that Nsr1 bypasses Whi5-mediated inhibition of SBF (Figure 6E). In effect, Nsr1 acts as a nutrient-dependent parallel input into SBF. As we have not been able to identify nutrient conditions in which loss of NSR1 causes a Start delay, we infer that NSR1 function is strongly buffered by other Start activators.

This model allows interpretation of some previous YLR053c/NSR1 genetic interactions uncovered in high-throughput studies(48). Deletion of NSR1 slightly aggravates the growth defect of a Ess1 prolyl isomerase mutant which in turn exhibits negative genetic interactions with deletions of SWI6 or SWI4 (49). Although the latter interactions suggested a possible role of Ess1 in Swi6/Whi5 nuclear import, we did not observe mis-localization of Swi4, Swi6 or Whi5 in GAL1-NSR1 and $n s r 1 \Delta$ strains. With respect to interactions with the transcriptional machinery, NSR1 overexpression exacerbates the defect caused by deletion of CTK1, the catalytic subunit of RNA Pol II C-terminal domain (CTD) kinase I (50). In contrast, NSR1 deletion shows a positive genetic interaction with the RNA Pol II CTD-associated phosphatase, FCP1, which negatively regulates transcription (51). NSR1 overexpression also subtly increases chromosomal instability (52), which might result from premature Start activation (53). These interactions with transcriptional regulators are consistent with our proposed model for Nsr1 function in G1/S transcription activation.

Nsr1 is a member of a newly described class of genetic elements variously called proto-genes, neo-ORFs, smORFS, small ORF encoded peptides, or microproteins (36, 54-62). Computational predictions and ribosomal footprinting first identified hundreds of short species-specific translated peptides from non-genic sequences in yeast (36). Subsequent approaches have yielded a plethora of microproteins encoded by smORFs in various species (54-57). Documented functions for microproteins include phagocytosis (58), mitochondrial function (59), actin-based motility (60) and mitotic chromosome segregation (61). De novo appearance of short proto-genes coupled with rapid evolution may form a dynamic reservoir for genetic innovation and diversification (36). Notably, fast evolving genes often have complex expression patterns 
compared to highly conserved genes and tend to be enriched for transcription-associated functions (63). As illustrated by the example of NSR1, transcription activation may be a particularly facile route for proto-genes to quickly acquire important regulatory functions that optimize fitness under specific conditions.

\section{Methods}

\section{Yeast strains construction and culture}

All strains were isogenic with the S288C (BY4741) background (Table S1). Standard molecular genetics methods were employed for genomic integration of C-terminal tagging cassettes (64). Standard media were used for yeast growth: rich (XY: $2 \%$ peptone, $1 \%$ yeast extract, $0.01 \%$ adenine, $0.02 \%$ tryptophan); synthetic complete (SC: $0.2 \%$ amino acids, $0.5 \%$ ammonium sulphate, $0.17 \%$ yeast nitrogen base); or nitrogen-poor $(0.17 \%$ YNB supplemented with $0.4 \%$ proline add histidine, leucine, methionine and uracil to complement auxotrophies as needed). Carbon sources were added to $2 \% \mathrm{w} / \mathrm{v}$ as indicated. Unless otherwise specified, cells were grown to saturation in SC+2\% glucose and diluted 1 in 5000 in fresh medium for 16-18h growth prior to experiments. These conditions ensured homeostatic growth in log-phase at the time of experiment at a culture density of $2-510^{6}$ cells $/ \mathrm{mL}$. For strains bearing constructs expressed under the inducible GAL1 promoter, the pre-growth stage was performed in SC+2\% raffinose, and galactose induction was performed as indicated. Cell size distributions were acquired using a Beckman Z2 Coulter Counter. Growth curves were acquired using a Tecan Sunrise shakerreader.

\section{SGA screen}

A cln3 $\triangle$ bck2 $\triangle$ GAL1-WHI5 strain was mated to an array of 5280 GAL1-ORF fusion strains (34). Following haploid selection, strains were scored for growth on selection medium containing $2 \%$ galactose. Three replicates of this screen were performed. For the third replicate, expression of the GAL4 transcription factor was increased in case it was limiting for expression of WHI5, the ORFs, or GAL genes required for growth in the presence of galactose at the sole carbon source. For this purpose, GAL4 was placed under the control of strong ADH1 promoter in a cln3::LEU2 
bck2::NAT ${ }^{R}$ whi5::Kan ${ }^{R}-p G A L 1-W H I 5$ can1d mfa1::MFA1pr-spHIS5+ GAL4p::HphRpADH1-GAL4 query strain. Screen hits were validated by transformation of the GAL1-GST-ORF construct directly into the $\ln 3 \triangle b c k 2 \triangle$ GAL1-WHI5 query strain. The YLR053c hit was also confirmed by tetrad analysis.

\section{Chromatin Immunoprecipitation}

Cells were grown in XY with 2\% raffinose, induced with $2 \%$ galactose for $6 \mathrm{~h}$ to an OD600 $\leq 0.5$ and fixed with $1 \%$ formaldehyde. Whole-cell extracts from $50 \mathrm{~mL}$ of culture were prepared by glass bead lysis, sonicated to shear chromatin DNA into fragments, and incubated with the appropriate antibody coupled to magnetic beads (Dynabeads PanMouse lgG). Immunoprecipitated DNA was washed, de-crosslinked, purified, and analyzed by quantitative real-time PCR. DNA reactions with appropriate oligonucleotides were set-up with SYBR Green PCR Master Mix (Applied Biosystems) and carried out on an ABI 7500 Fast Real-Time PCR System. Enrichment at the CLN2 or PCL1 locus was determined after normalization against values obtained from input samples using SYP1 as the reference gene.

\section{Immunoprecipitation and immunoblot analysis}

Protein extracts were prepared in lysis buffer $(10 \mathrm{mM}$ HEPES-KOH pH 7.9, $50 \mathrm{mM} \mathrm{KCl}, 1.5 \mathrm{mM}$ $\mathrm{MgCl} 2,1 \mathrm{~mm}$ EDTA, 0.5mM DTT, 50mM NaF, 50mM sodium pyrophosphate, 1mM Na3VO4 and Roche protease inhibitor cocktail) by glass bead lysis. Immunoaffinity purifications were carried out at $4^{\circ} \mathrm{C}$ for $2 \mathrm{~h}$ with indicated antibodies, beads were washed 3 times with wash buffer (10mM Tris-Cl pH7.9, 0.1\% Triton X-100, 0.5mM DTT, 0.2mM EDTA, 10\% glycerol, 150mM NaCl), and resuspended in SDS sample buffer. Proteins were resolved by SDS-PAGE, transferred onto nitrocellulose membrane and immunoblotted with anti-HA, anti-Swi4 or anti-Swi6 (gift from Brenda Andrews), anti-GST, anti-Sic1 or 9E10 monoclonal antibodies, followed by detection with HRP-conjugated secondary antibody $(12,65)$. For phosphatase assays, immunoprecipitates were incubated at $37^{\circ} \mathrm{C}$ for $1 \mathrm{~h}$ in either buffer or $600 \mathrm{U}$ of lambda $(\lambda)$-phosphatase with or without phosphatase inhibitors prior to SDS-PAGE and immunoblot detection. 


\section{In vitro binding assays}

Recombinant GST-Nsr1 fusion protein was affinity purified with GSH-Sepharose 4B (Amersham Biosciences) in 50 mM HEPES-NaOH, pH 7.5, 150 mM NaCl, 5 mM EDTA, 5mM NaF, 0.1\% NP-40, 10\% glycerol, supplemented with 1mM PMSF. Recombinant SBF or MBF complex was purified with anti-FLAG resin (M2, Sigma) from insect cells co-infected with FlagSwi6/Swi6 or FlagMbp1/Swi6 baculovirus, in buffer supplemented with complete protease inhibitor cocktail (Roche), and then eluted with excess FLAG peptide (12). Binding reactions were incubated at $4^{\circ} \mathrm{C}$ for $1 \mathrm{~h}$ with rotation. Washed samples were resolved on SDS-PAGE gel followed by immunoblotting with anti-FLAG (M2, Sigma) and anti-Swi6. For competition assays, Clb5-Cdc28 complexes were isolated from yeast cultures using anti-Clb5 antibodies. SBF-GST-Nsr1 and SBFHA-Whi5 complexes were pre-formed in solution and immobilized on anti-FLAG and anti-HA resin, respectively, incubated with GST-Nsr1, HA-Whi5 or both Clb5/Cdc28 and GST-Nsr1, washed and analyzed as described above.

\section{Immunoprecipitation and mass spectrometry analysis}

Cell pellets from untagged and $\mathrm{Nsr}^{13 \mathrm{MYC}}$ strains from $100 \mathrm{~mL}$ of culture at $\mathrm{OD}_{600}=1$ were lysed in standard lysis buffer $(50 \mathrm{mM}$ Tris- $\mathrm{HCl}$ pH8.0, $150 \mathrm{mM} \mathrm{KCl}, 100 \mathrm{mM} \mathrm{NaF}, 10 \%$ glycerol, $0.1 \%$ tween-20, 1mM tungstate, 1mM DTT, 10mM AEBSF, $10 \mathrm{mM}$ pepstatin A, $10 \mathrm{mM}$ E-64) (43) supplemented with protease inhibitors using a $\mathrm{N}_{2}(\mathrm{I})$ freezer mill. Lysates $(0.5 \mathrm{~mL})$ were incubated for $1 \mathrm{~h}$ with $5 \mu \mathrm{L}$ of anti-MYC antibody (Gentex) followed by $1 \mathrm{~h}$ incubation with an additional 50 $\mu \mathrm{L}$ of GammaBind plus Sepharose beads (GE Healthcare) to capture protein complexes. After multiple washes, samples were separated on BioRad precast gels and the entire gel lane was cut for each sample (CAPCA core facility, https://capca.iric.ca/; see Supplemental Methods). Gel samples were destained, alkylated and digested with trypsin for $8 \mathrm{~h}$ at $37^{\circ} \mathrm{C}$ and peptides extracted in $90 \%$ ACN. Peptides were separated on a home-made C18 column connected to QExactive HF Biopharma with a 56 min gradient of $0 \%$ to $30 \%$ acetonitrile in $0.2 \%$ formic acid. Each full MS spectrum of extracted peptides was acquired at a resolution of 120,000 , followed by acquisition of 15 tandem-MS (MS-MS) spectra on the most abundant multiply charged precursor ions by collision-induced dissociation (HCD). Data were processed using PEAKS X (Bioinformatics 
Solutions, Waterloo, ON) and the UniProt yeast database. Variable selected posttranslational modifications were carbamidomethyl (C), oxidation (M), deamidation (NQ), acetyl (N-ter) and phosphorylation (STY). Control untagged and Nsr1 ${ }^{13 \mathrm{MYC}}$ data were analyzed with Scaffold 4.8.9 at a false-discovery rate (FDR) of $1 \%$ for at least 2 peptides with a likelihood of at least $99 \%$.

\section{High-content imaging}

High-content images were acquired on an OPERA high-throughput confocal microscope (PerkinElmer) equipped with a 60x water objective. Pixel resolution was $220 \mathrm{~nm}$ at $2 * 2$ binning. $200 \mu \mathrm{L}$ of culture were directly transferred to a Greiner Screenstar glass-bottom 96 well imaging plate, and imaged within 30-45 minutes. GFP was excited with a $488 \mathrm{~nm}$ laser (800 ms exposure for endogenously tagged proteins, $320 \mathrm{~ms}$ for overexpressed proteins), and detected using a 520/35 nm band-pass filter. For WHI5-GFP and WHI5-NSR1-GFP strains, pre-Start G1 phase cells were identified by nuclear localization of the GFP signal, as computed using a custom imageanalysis script written in MATLAB (MathWorks). The script masks individual cells using thresholdbased detection of the autofluorescence background, and determines the fraction of individual cells that display a pre-Start nuclear localization of the GFP signal.

\section{sN\&B and RICS fluorescence fluctuation microscopy}

Live cells in log-phase were imaged on a ISS Alba sN\&B system comprised of an inverted confocal Nikon Eclipse microscope equipped with a 100x water objective, a Fianium Whitelase continuous white laser with $488 \mathrm{~nm}$ emission filters and single photon APD detectors, as described previously (30). In brief, $1.5 \mathrm{~mL}$ of cell culture was pelleted for $2 \mathrm{~min}$ at $3000 \mathrm{rpm}$, resuspended in 100 $\mu \mathrm{L}$ of culture supernatant and $3 \mu \mathrm{L}$ deposited on a pre-set $65 \mu \mathrm{L}$ drop of $\mathrm{SC}+2 \%$ glucose $+2 \%$ agar gel medium on a circular glass coverslip (\#1, VWR) that was encircled by an adhesive silicon ring. After 4 min drying time, a ConcanavalinA-coated (Sigma, $2 \mathrm{mg} / \mathrm{mL}$ ) coverslip was gently pressed on top of the agarose to seal the pad against the adhesive silicon ring. Sealed pads were clamped in an AttoFluor chamber (Molecular Probes) and immediately imaged for no more than $1.5 \mathrm{~h}$. Unless otherwise specified, the culture growth medium was re-used to make the imaging pads in order to prevent inadvertent nutrient up- or down-shifts. For this purpose, $1 \mathrm{~mL}$ of cell culture 
was pelleted at $15000 \mathrm{rpm}$ for $1 \mathrm{~min}$ and $500 \mu \mathrm{L}$ of the supernatant was mixed with $10 \mathrm{mg}$ of agarose and warmed for $1-2 \mathrm{~min}$ at $98^{\circ} \mathrm{C}$ to melt the agar, followed by application to a coverslip. For sN\&B experiments in the presence of rapamycin, growth medium containing $100 \mathrm{nM}$ rapamycin was also used to prepare the pad. To mitigate possible degradation of rapamycin during the pad preparation, an additional $100 \mathrm{nM}$ of rapamycin was added to the pre-warmed agar mix just before making the pad.

sN\&B imaging was performed using 20 raster scans of the same $30 \mu \mathrm{m}$-wide Fields of View (FOVs) of 256 pixels (pixel size $117 \mathrm{~nm}$ ), using an excitation power of 1-2 $\mu \mathrm{W}$ at $488 \mathrm{~nm}$ wavelength and a $64 \mu$ s pixel dwell time. sN\&B images shown in the figures are projections of the 20 raster scans. Protein concentrations were extracted from sN\&B data using custom analysis software (30). RICS imaging was performed in a similar fashion to sN\&B imaging but different parameters were used to improve correlation curves (pixel size of $48.8 \mathrm{~nm}, 50$ frames, $20 \mu$ s pixel dwell time) as described previously (43). RICS vertical correlations for individual FOVs were fitted to single mode-free diffusion models using the SimFCS analysis software. FOVs of poor-quality fit were discarded from diffusion coefficients plots.

\section{Bioinformatics}

The sequences of orthologs of YLR053c were obtained from the Fungal Orthogroups website. For S. paradoxus and S. mikatae, where no ORF was predicted at the expected locus, the YLR053c sequence was searched against whole genome assemblies using TBLASTN 2.2.27 to predict orthologs. The synteny of the regions in $K$. waltii and S. cerevisae was confirmed based on Orthogroups orthology assignments of the upstream (47.17997 and IES3) and downstream (47.18006 and OSW2) genes and the fact that each of these assignments were supported by highly significant Blast e-values. Alignments were generated using ClustalO 1.2.0 and displayed using the MView online tool.

\section{Mathematical model of Start}

Whisker and box plots for model predictions of the critical size at Start were obtained using the mathematical model and the data processing procedure described previously (30). For each plot, 
50 individual cells bearing variable Whi5 concentrations randomly picked in the $100-140 \mathrm{nM}$ (for the Whi5-GFP strain) and 65-105nM (for the Whi5-Nsr1-GFP strain) ranges were simulated, and plots generated in Excel using standard statistics of the distributions of critical size values for each strain.

\section{Data Availability}

The mass spectrometry proteomics data have been deposited to the ProteomeXchange Consortium via the PRIDE (66) partner repository with the dataset identifier PXD018681 and DOI 10.6019/PXD018681.

\section{Acknowledgments}

We thank Marc Angeli for technical assistance with SGA screens and Brenda Andrews for providing reagents and strains. This work was supported by a grant from the Canadian Institutes of Health Research (FDN-167277) to M.T., a Genomics Technology Platform award from Genome Canada to M.T. and P.T., a Genomics Applications Partnership Program award from Genome Canada and Genome Quebec to P.T., an Institute for Data Valorisation (IVADO) postdoctoral fellowship to J.C.-H., and a Canada Research Chair in Systems and Synthetic Biology to M. T.

\section{Competing interests}

The authors declare no competing interests.

\section{Author contributions}

Conceptualization: J.S., S.T., M.T.; Data Curation: S.T., J.C-H.; Formal Analysis: S.T., J.C-H.; Funding Acquisition: M.T.; Investigation and Validation: S.T., J.S., Y.T., J.T., S.M., D.B.; Methodology: S.T., J.S., J.T., S.M., C.A.R., M.T.; Project Administration and Supervision: S.T., M.T.; Resources: S.T., J.S., Y.T., J.T., S.M., D.B.; Software: S.T., J.C-H.; Visualization: S.T., J.S., Y.T; Writing - Original Draft Preparation: S.T., J.S., D.B.; Writing - Review \& Editing: S.T., Y.T., J.C-H., C.A.R., M.T.

\section{$\underline{\text { References }}$}


1. Broach JR. Nutritional control of growth and development in yeast. Genetics. 2012;192(1):73-105. 2. Johnston GC, Pringle JR, Hartwell LH. Coordination of growth with cell division in the yeast Saccharomyces cerevisiae. Exp Cell Res. 1977;105(1):79-98.

3. Jorgensen P, Tyers M. How cells coordinate growth and division. Curr Biol. 2004;14(23):R1014-27. 4. Lowndes NF, Johnson AL, Breeden L, Johnston LH. SWI6 protein is required for transcription of the periodically expressed DNA synthesis genes in budding yeast. Nature. 1992;357(6378):505-8.

5. Primig M, Sockanathan S, Auer H, Nasmyth K. Anatomy of a transcription factor important for the start of the cell cycle in Saccharomyces cerevisiae. Nature. 1992;358(6387):593-7.

6. Koch C, Moll T, Neuberg M, Ahorn H, Nasmyth K. A role for the transcription factors Mbp1 and Swi4 in progression from G1 to S phase. Science. 1993;261(5128):1551-7.

7. Iyer VR, Horak CE, Scafe CS, Botstein D, Snyder M, Brown PO. Genomic binding sites of the yeast cell-cycle transcription factors SBF and MBF. Nature. 2001;409(6819):533-8.

8. Lee TI, Rinaldi NJ, Robert F, Odom DT, Bar-Joseph Z, Gerber GK, et al. Transcriptional regulatory networks in Saccharomyces cerevisiae. Science. 2002;298(5594):799-804.

9. Simon I, Barnett J, Hannett N, Harbison CT, Rinaldi NJ, Volkert TL, et al. Serial regulation of transcriptional regulators in the yeast cell cycle. Cell. 2001;106(6):697-708.

10. Ferrezuelo F, Colomina N, Futcher B, Aldea M. The transcriptional network activated by Cln3 cyclin at the G1-to-S transition of the yeast cell cycle. Genome Biol. 2010;11(6):R67.

11. Jorgensen P, Nishikawa JL, Breitkreutz BJ, Tyers M. Systematic identification of pathways that couple cell growth and division in yeast. Science. 2002;297(5580):395-400.

12. Costanzo M, Nishikawa JL, Tang X, Millman JS, Schub O, Breitkreuz K, et al. CDK activity antagonizes Whi5, an inhibitor of G1/S transcription in yeast. Cell. 2004;117(7):899-913.

13. de Bruin RA, McDonald WH, Kalashnikova TI, Yates J, 3rd, Wittenberg C. Cln3 activates G1-specific transcription via phosphorylation of the SBF bound repressor Whi5. Cell. 2004;117(7):887-98.

14. Wagner MV, Smolka MB, de Bruin RA, Zhou H, Wittenberg C, Dowdy SF. Whi5 regulation by site specific CDK-phosphorylation in Saccharomyces cerevisiae. PLoS One. 2009;4(1):e4300.

15. Skotheim JM, Di Talia S, Siggia ED, Cross FR. Positive feedback of G1 cyclins ensures coherent cell cycle entry. Nature. 2008;454(7202):291-6.

16. Tyers M, Tokiwa G, Futcher B. Comparison of the Saccharomyces cerevisiae G1 cyclins: Cln3 may be an upstream activator of Cln1, Cln2 and other cyclins. EMBO J. 1993;12(5):1955-68.

17. Mclnerny CJ, Partridge JF, Mikesell GE, Creemer DP, Breeden LL. A novel Mcm1-dependent element in the SWI4, CLN3, CDC6, and CDC47 promoters activates M/G1-specific transcription. Genes Dev. 1997;11(10):1277-88.

18. Nash R, Tokiwa G, Anand S, Erickson K, Futcher AB. The WHI1+ gene of Saccharomyces cerevisiae tethers cell division to cell size and is a cyclin homolog. EMBO J. 1988;7(13):4335-46.

19. Liu X, Wang X, Yang X, Liu S, Jiang L, Qu Y, et al. Reliable cell cycle commitment in budding yeast is ensured by signal integration. Elife. 2015;4.

20. Litsios A, Huberts D, Terpstra HM, Guerra P, Schmidt A, Buczak K, et al. Differential scaling between $\mathrm{G} 1$ protein production and cell size dynamics promotes commitment to the cell division cycle in budding yeast. Nat Cell Biol. 2019;21(11):1382-92.

21. Wijnen $\mathrm{H}$, Futcher B. Genetic analysis of the shared role of CLN3 and BCK2 at the G(1)-S transition in Saccharomyces cerevisiae. Genetics. 1999;153(3):1131-43.

22. Bastajian N, Friesen $\mathrm{H}$, Andrews BJ. Bck2 acts through the MADS box protein $\mathrm{Mcm} 1$ to activate cell-cycle-regulated genes in budding yeast. PLoS Genet. 2013;9(5):e1003507.

23. Tokiwa G, Tyers M, Volpe T, Futcher B. Inhibition of G1 cyclin activity by the Ras/cAMP pathway in yeast. Nature. 1994;371(6495):342-5.

24. Flick K, Chapman-Shimshoni D, Stuart D, Guaderrama M, Wittenberg C. Regulation of cell size by glucose is exerted via repression of the CLN1 promoter. Mol Cell Biol. 1998;18(5):2492-501. 
25. Jorgensen P, Rupes I, Sharom JR, Schneper L, Broach JR, Tyers M. A dynamic transcriptional network communicates growth potential to ribosome synthesis and critical cell size. Genes Dev. 2004;18(20):2491-505.

26. Lempiainen $H$, Uotila A, Urban J, Dohnal I, Ammerer G, Loewith $R$, et al. Sfp1 interaction with TORC1 and Mrs6 reveals feedback regulation on TOR signaling. Mol Cell. 2009;33(6):704-16.

27. Singh J, Tyers M. A Rab escort protein integrates the secretion system with TOR signaling and ribosome biogenesis. Genes Dev. 2009;23(16):1944-58.

28. Urban J, Soulard A, Huber A, Lippman S, Mukhopadhyay D, Deloche O, et al. Sch9 is a major target of TORC1 in Saccharomyces cerevisiae. Mol Cell. 2007;26(5):663-74.

29. Talarek N, Gueydon E, Schwob E. Homeostatic control of START through negative feedback between Cln3-Cdk1 and Rim15/Greatwall kinase in budding yeast. Elife. 2017;6.

30. Dorsey S, Tollis S, Cheng J, Black L, Notley S, Tyers M, et al. G1/S Transcription Factor Copy Number Is a Growth-Dependent Determinant of Cell Cycle Commitment in Yeast. Cell Syst. 2018;6(5):539-54 e11.

31. Epstein CB, Cross FR. Genes that can bypass the CLN requirement for Saccharomyces cerevisiae cell cycle START. Mol Cell Biol. 1994;14(3):2041-7.

32. Di Como CJ, Chang H, Arndt KT. Activation of CLN1 and CLN2 G1 cyclin gene expression by BCK2. Mol Cell Biol. 1995;15(4):1835-46.

33. Tong AH, Evangelista M, Parsons AB, Xu H, Bader GD, Page N, et al. Systematic genetic analysis with ordered arrays of yeast deletion mutants. Science. 2001;294(5550):2364-8.

34. Sopko R, Huang D, Preston N, Chua G, Papp B, Kafadar K, et al. Mapping pathways and phenotypes by systematic gene overexpression. Mol Cell. 2006;21(3):319-30.

35. Zhu H, Bilgin M, Bangham R, Hall D, Casamayor A, Bertone P, et al. Global analysis of protein activities using proteome chips. Science. 2001;293(5537):2101-5.

36. Carvunis AR, Rolland T, Wapinski I, Calderwood MA, Yildirim MA, Simonis N, et al. Proto-genes and de novo gene birth. Nature. 2012;487(7407):370-4.

37. Digman MA, Dalal R, Horwitz AF, Gratton E. Mapping the number of molecules and brightness in the laser scanning microscope. Biophys J. 2008;94(6):2320-32.

38. Balleza E, Kim JM, Cluzel P. Systematic characterization of maturation time of fluorescent proteins in living cells. Nat Methods. 2018;15(1):47-51.

39. Daran-Lapujade P, Jansen ML, Daran JM, van Gulik W, de Winde JH, Pronk JT. Role of transcriptional regulation in controlling fluxes in central carbon metabolism of Saccharomyces cerevisiae. A chemostat culture study. J Biol Chem. 2004;279(10):9125-38.

40. Boer VM, de Winde JH, Pronk JT, Piper MD. The genome-wide transcriptional responses of Saccharomyces cerevisiae grown on glucose in aerobic chemostat cultures limited for carbon, nitrogen, phosphorus, or sulfur. J Biol Chem. 2003;278(5):3265-74.

41. Brown CM, Dalal RB, Hebert B, Digman MA, Horwitz AR, Gratton E. Raster image correlation spectroscopy (RICS) for measuring fast protein dynamics and concentrations with a commercial laser scanning confocal microscope. J Microsc. 2008;229(Pt 1):78-91.

42. Digman MA, Wiseman PW, Horwitz AR, Gratton E. Detecting protein complexes in living cells from laser scanning confocal image sequences by the cross correlation raster image spectroscopy method. Biophys J. 2009;96(2):707-16.

43. Thattikota Y, Tollis S, Palou R, Vinet J, Tyers M, D'Amours D. Cdc48/VCP Promotes Chromosome Morphogenesis by Releasing Condensin from Self-Entrapment in Chromatin. Mol Cell. 2018;69(4):664-76 e5.

44. Gray JV, Ogas JP, Kamada Y, Stone M, Levin DE, Herskowitz I. A role for the Pkc1 MAP kinase pathway of Saccharomyces cerevisiae in bud emergence and identification of a putative upstream regulator. EMBO J. 1997;16(16):4924-37. 
45. Adames NR, Schuck PL, Chen KC, Murali TM, Tyson JJ, Peccoud J. Experimental testing of a new integrated model of the budding yeast Start transition. Mol Biol Cell. 2015;26(22):3966-84.

46. Beck T, Hall MN. The TOR signalling pathway controls nuclear localization of nutrient-regulated transcription factors. Nature. 1999;402(6762):689-92.

47. Minehart PL, Magasanik B. Sequence and expression of GLN3, a positive nitrogen regulatory gene of Saccharomyces cerevisiae encoding a protein with a putative zinc finger DNA-binding domain. Mol Cell Biol. 1991;11(12):6216-28.

48. Oughtred R, Stark C, Breitkreutz BJ, Rust J, Boucher L, Chang C, et al. The BioGRID interaction database: 2019 update. Nucleic Acids Res. 2019;47(D1):D529-D41.

49. Atencio D, Barnes C, Duncan TM, Willis IM, Hanes SD. The yeast Ess1 prolyl isomerase controls Swi6 and Whi5 nuclear localization. G3 (Bethesda). 2014;4(3):523-37.

50. Sharifpoor S, van Dyk D, Costanzo M, Baryshnikova A, Friesen H, Douglas AC, et al. Functional wiring of the yeast kinome revealed by global analysis of genetic network motifs. Genome Res. 2012;22(4):791-801.

51. Costanzo M, VanderSluis B, Koch EN, Baryshnikova A, Pons C, Tan G, et al. A global genetic interaction network maps a wiring diagram of cellular function. Science. 2016;353(6306).

52. Frumkin JP, Patra BN, Sevold A, Ganguly K, Patel C, Yoon S, et al. The interplay between chromosome stability and cell cycle control explored through gene-gene interaction and computational simulation. Nucleic Acids Res. 2016;44(17):8073-85.

53. Tanaka S, Diffley JF. Deregulated G1-cyclin expression induces genomic instability by preventing efficient pre-RC formation. Genes Dev. 2002;16(20):2639-49.

54. Ma J, Ward CC, Jungreis I, Slavoff SA, Schwaid AG, Neveu J, et al. Discovery of human sORFencoded polypeptides (SEPs) in cell lines and tissue. J Proteome Res. 2014;13(3):1757-65.

55. Ladoukakis E, Pereira V, Magny EG, Eyre-Walker A, Couso JP. Hundreds of putatively functional small open reading frames in Drosophila. Genome Biol. 2011;12(11):R118.

56. Kastenmayer JP, Ni L, Chu A, Kitchen LE, Au WC, Yang H, et al. Functional genomics of genes with small open reading frames (sORFs) in S. cerevisiae. Genome Res. 2006;16(3):365-73.

57. Ma J, Diedrich JK, Jungreis I, Donaldson C, Vaughan J, Kellis M, et al. Improved Identification and Analysis of Small Open Reading Frame Encoded Polypeptides. Anal Chem. 2016;88(7):3967-75.

58. Pueyo JI, Magny EG, Sampson CJ, Amin U, Evans IR, Bishop SA, et al. Hemotin, a Regulator of Phagocytosis Encoded by a Small ORF and Conserved across Metazoans. PLoS Biol. 2016;14(3):e1002395. 59. Gong Z, Tasset I, Diaz A, Anguiano J, Tas E, Cui L, et al. Humanin is an endogenous activator of chaperone-mediated autophagy. J Cell Biol. 2018;217(2):635-47.

60. Polycarpou-Schwarz M, Gross M, Mestdagh P, Schott J, Grund SE, Hildenbrand C, et al. The cancerassociated microprotein CASIMO1 controls cell proliferation and interacts with squalene epoxidase modulating lipid droplet formation. Oncogene. 2018;37(34):4750-68.

61. Li JM, Li Y, Elledge SJ. Genetic analysis of the kinetochore DASH complex reveals an antagonistic relationship with the ras/protein kinase A pathway and a novel subunit required for Ask1 association. Mol Cell Biol. 2005;25(2):767-78.

62. Saghatelian A, Couso JP. Discovery and characterization of smORF-encoded bioactive polypeptides. Nat Chem Biol. 2015;11(12):909-16.

63. Coulombe-Huntington J, Xia Y. Network Centrality Analysis in Fungi Reveals Complex Regulation of Lost and Gained Genes. PLoS One. 2017;12(1):e0169459.

64. Fink GR. Guide to Yeast Genetics and Molecular and Cell Biology. Guthrie C, editor. San Francisco, California: Academic Press, Elsevier; 2002. 12 p.

65. Tang X, Orlicky S, Mittag T, Csizmok V, Pawson T, Forman-Kay JD, et al. Composite low affinity interactions dictate recognition of the cyclin-dependent kinase inhibitor Sic1 by the SCFCdc4 ubiquitin ligase. Proc Natl Acad Sci U S A. 2012;109(9):3287-92. 
bioRxiv preprint doi: https://doi.org/10.1101/2020.04.20.033787; this version posted April 20, 2020. The copyright holder for this preprint (which was not certified by peer review) is the author/funder. All rights reserved. No reuse allowed without permission.

66. Perez-Riverol Y, Csordas A, Bai J, Bernal-Llinares M, Hewapathirana S, Kundu DJ, et al. The PRIDE database and related tools and resources in 2019: improving support for quantification data. Nucleic Acids Res. 2019;47(D1):D442-D50. 


\section{Figure and Table Legends}

Figure 1: A genome-wide screen identifies YLR053c/NSR1 as a dosage suppressor of cln3D

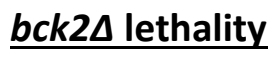

(A) Schematic of SGA genetic screen for dosage suppressors of $c \ln 3 \Delta b c k 2 \Delta$ lethality. (B) Representative screen plate scored for growth on galactose medium. Red box, GAL1-YLR053c. (C) Comparison of growth at $30^{\circ} \mathrm{C}$ for the indicated strains streaked onto either glucose or galactose medium. (D) Chromosomal region around YLR053c/NSR1 on Chr. XII and translated 108 amino acid (12.7 kDa) protein sequence. (E) Ylr053c/Nsr1 protein sequence in S. cerevisiae (top) aligned with sequences of other yeast species. Conservation of a KKXNPFYVPSXVVREMV motif at the Cterminal across evolutionary distant species is indicated by a red bar.

Table 1: Other dosage suppressors of the $\ln 3 \Delta$ bck2 $\Delta$ lethality

Genes identified in our three SGA-based genome-wide screens as dosage suppressors of the cln3 3 bck2 $\Delta$ lethality. Genes are grouped according to whether they were identified in the 3 screens (first group, 12 genes), in 2 screens out of 3 (second group, 22 genes) or only once (third group, 63 genes). YLRO53c/NSR1 belongs to the first group and is indicated in red.

Figure 2: Nitrogen deprivation and rapamycin treatment induce cell cycle-regulated Nsr1 expression

(A) sN\&B images of untagged and NSR1-GFP strains. Cells were grown and imaged in $\mathrm{SC}+2 \%$ glucose with or without $100 \mathrm{nM}$ rapamycin, $\mathrm{SC}+2 \%$ raffinose or YNB+0.4\%proline+2\%glucose+HIS, LEU, MET, URA (referred to as YNB pro glu), as indicated. Scale bar is $10 \mu \mathrm{m}$. The same intensity scale was used for all conditions. (B) Abundance of MYC-tagged Nsr1 in various nutrient conditions as determined by immunoblot of anti-MYC immune complexes. IgG indicates antibody light chain. (C) Absolute Nsr1 concentration in single cells grown and imaged in YNB pro glu as a function of cell size, as determined by sN\&B. Blue and orange dots represent individual cells from two different experiments. The typical size range of cells at the G1/S transition (800-1000 pixels, corresponding to 27-38 fL) is indicated. Cellaveraged total Nsr1 concentration (top) and nuclear concentration where Nsr1 nuclear 
localization was evident (bottom) are shown. Infrequent small cells with high Nsr1 levels had high autofluorescence and no nuclear localization of the signal. (D) High-content confocal image of log-phase Nsr1-GFP cells grown and imaged in YNB pro glu.

\section{Figure 3: NSR1 is genetically upstream of SBF}

Cell size distributions were determined for the indicated genetic combinations. (A) Effect of NSR1 overexpression alone. (B) Interaction of NSR1 overexpression with $c \ln 3 \Delta$ and $b c k 2 \Delta$ mutations. (C) Interaction of NSR1 overexpression and nsr1 1 mutation with WHI5 overexpression and whi5 mutation. (D) Interaction of NSR1 overexpression with swi4A and swi6A mutations. (E) Interaction of NSR1 overexpression with swi4-ts mutation. Strains were transformed with GAL1NSR1, GAL1-WHI5 plasmids or empty vector controls as indicated. Strains bearing galactoseregulated constructs and associated controls were induced for $6 \mathrm{~h}$ in $\mathrm{SC}+2 \%$ galactose before size determination. WT plots in panels B, C and D (left, middle) represent the same measurement.

\section{Figure 4: Nsr1 binds to SBF and SBF-regulated promoter DNA}

(A) Nsr1 ${ }^{13 M Y C}$, Swi4, or Swi6 complexes were immunoprecipitated from a rapamycin-treated Nsr1 ${ }^{13 M Y C}$ strain and interacting proteins assessed by immunoblot. Co-immunoprecipitation of

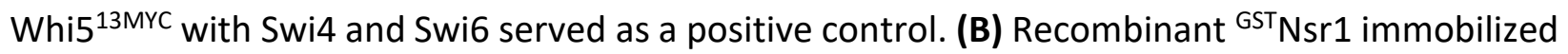
on GSH-Sepharose resin was incubated with increasing concentrations of purified SBF ( ${ }^{\text {Flagswi4- }}$ Swi6) or MBF (FlagMbp1-Swi6). Bound proteins were analysed by SDS-PAGE electrophoresis and immunoblotting with anti-Swi6 and anti-Flag antibodies as indicated. GSH-Sepharose resin alone served as a negative control. (C) Anti-MYC chromatin immunoprecipitations from wild-type untagged control and $n s r 1:: N S R 1^{13 M Y C}$ strains either untreated or treated with $200 \mathrm{ng} / \mathrm{mL}$ of rapamycin for $2 \mathrm{~h}$ were probed for the presence of CLN2 and PCL1 promoter DNA sequences by real time PCR. (D) Top panel: RICS vertical correlations from Nsr1-GFP cells grown in YNB pro glu as a function of the pixel shift for total and cytosolic Nsr1-GFP pools. RICS correlation for free GFP was used as a control for unconstrained diffusion. Data points show correlation averages over $\mathrm{N}$ fields of view (FOV, N=25 for nuclear Nsr1, N=7 for cytosolic Nsr1, N=12 for free GFP). Each FOV contained 1-5 cells. Error bars represent the standard error on the mean. Bottom panel: Scatter 
plots of fitted diffusion coefficients from individual FOVs of the same strains. Data from Swi6-GFP FOVs served as a control for constrained diffusion due to a strong interaction with DNA.

\section{Figure 5: Nsr1 transcription function rescues G1/S-transcription deficient mutants}

(A) Transactivation of a HIS3 reporter by fusion of Nsr1 to the Gal4 DNA binding domain (DBD) but not by fusion of the Nsr1 C-terminus. GAL4-DBD-UBE2G2 and GAL4-DBD constructs served as positive and negative controls, respectively. Growth curves were determined in -His -Trp medium. (B) Serial 5-fold dilutions of NSR1 and GAL1-NSR1 strains in the WT, swi4-ts, mbp1 $\Delta$ and mbp1 1 swi4-ts backgrounds were spotted onto $\mathrm{SC}+2 \%$ glucose, $\mathrm{SC}+2 \%$ raffinose and $\mathrm{SC}+2 \%$ galactose, and grown for 5 days at $30^{\circ} \mathrm{C}$. (C) Serial 5-fold dilutions of WT or swi6 4 strains transformed with GAL1-WHI5, GAL1-WHI5 ${ }^{12 A}$, GAL1-SWI6 SA4, GAL1-NSR1 or empty control plasmids or combinations thereof as indicated. Cells were spotted on rich medium containing $2 \%$ glucose or $2 \%$ galactose and grown for 2 days at $30^{\circ} \mathrm{C}$.

\section{Figure 6: Nsr1 bypasses Whi5 inhibition of SBF}

(A) sN\&B microscopy images of Whi5-GFP and Whi5-Nsr1-GFP cells grown in SC+2\% glucose. Scale bars are $5 \mu \mathrm{m}$. The same intensity scale was used on both images. Fractions of pre-Start G1 cells were computed based on the assessment of nuclear GFP signal in Whi5-GFP cells ( $N=245$ ) and Whi5-Nsr1-GFP (N=95) cells. Absolute concentrations of Whi5-GFP and Whi5-Nsr1-GFP are shown in the plot. (B) Cell size distributions of WT (black), GAL1-NSR1 (blue), whi5 $\Delta$ (red) and WHI5-NSR1-GFP (purple) strains in SC+2\% glucose. (C) Cell size distributions of WT (black), GAL1NSR1 (blue), whi5A(red) and WHI5-NSR1-GFP (purple) strains in SC+2\% galactose. (D) Genotyping of 10 tetrads from a cln3 $\Delta$ WHI5-NSR1-GFP X bck2 $\Delta$ cross (top) and a cln3 $\Delta$ WHI5GFP X bck2 $\Delta$ cross (bottom). For each tetrad, spore clone growth was assessed on SD-LEU (indicates $c \ln 3:: L E U 2$ ), SC+NAT (indicates $b c k 2:: N A T^{R}$ ), and SD-HIS (indicates whi5::WHI5-NSR1GFP-HIS3 or whi5::WHI5-GFP-HIS3). Coloured boxes indicate viable cln3 $\Delta$ bck2 $\Delta$ spore clones, all of which also contained the WHI5-NSR1-GFP construct. (F) Simplified schematic for Nsr1dependent activation of Start. Red lines indicate nitrogen limited conditions. Not all components of the Start machinery are shown. See text for details. 
bioRxiv preprint doi: https://doi.org/10.1101/2020.04.20.033787; this version posted April 20, 2020. The copyright holder for this preprint (which was not certified by peer review) is the author/funder. All rights reserved. No reuse allowed without permission. 
bioRxiv preprint doi: https://doi.org/10.1101/2020.04.20.033787; this version posted April 20, 2020. The copyright holder for this preprint (which

A
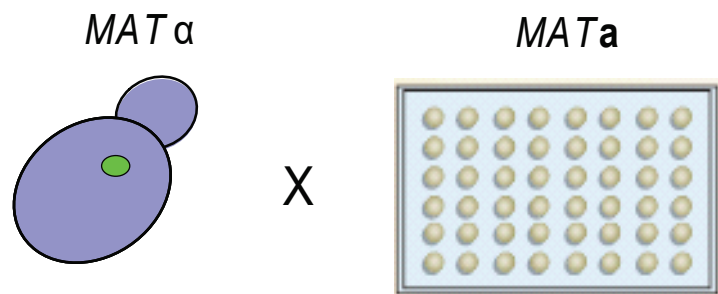

cln3 $\Delta$ bck2 $\Delta$

GAL1-WHI5

was not certified by peer review) is the author/funder. All rights reserved. No reuse allowed without permission.
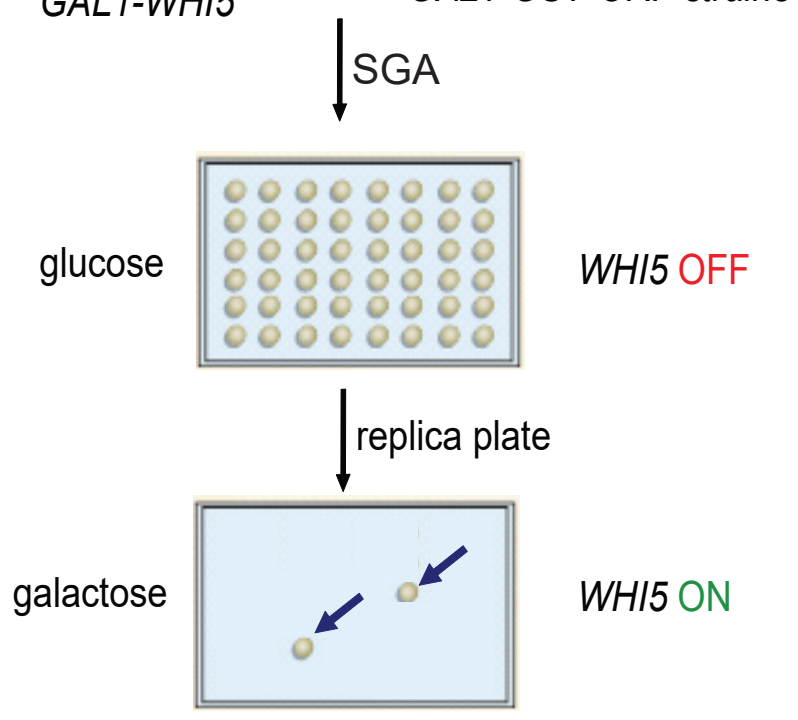

score bypass lethality

(GAL1-YLR053c)

\section{galactose}

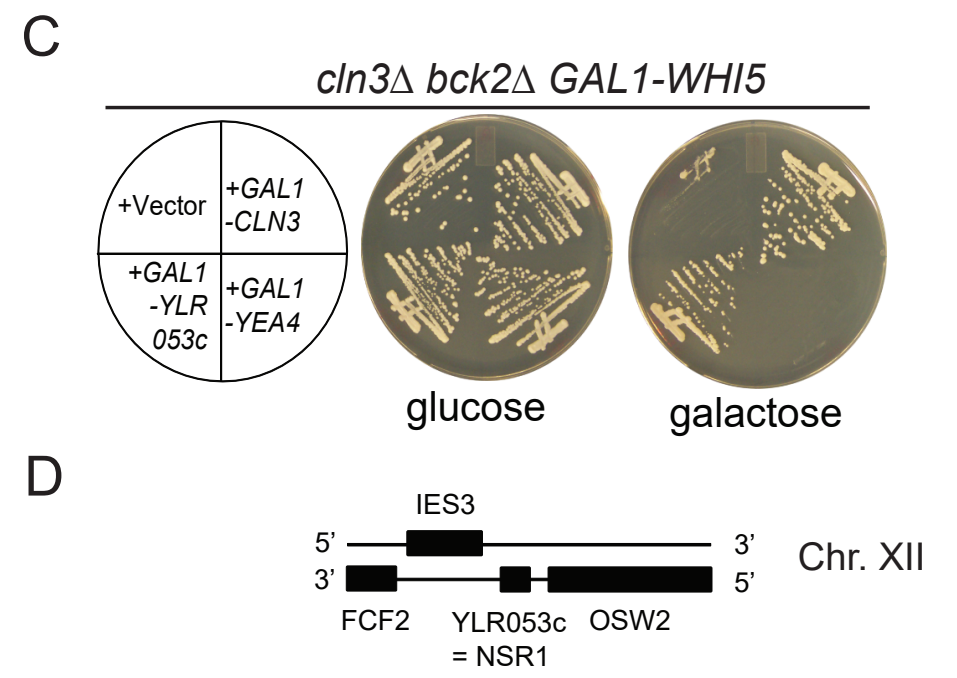
1 MDMLHNKCSD AIKSTSNSNL SNEVDKQKLQ YDDLGNTGFS ELFEMESQDN 51 NDSIEDFLFF NINLTQEVEF ENQRQYEHTK KTKKHNPFYV PSEWREMVK 101 KHALNGRI*

\footnotetext{
1 Scas|Scas656.13d

2 Kwal|Kwal47.18002

3 Scer|YLR053C

4 Sbay|sbayc672-g32.1 $51.4 \% \quad 12.1 \%$ consensus $100 \%$

consensus $/ 90 \%$

consensus $/ 80 \%$

consensus $/ 70 \%$

cov pid $100.0 \% \quad 100.0 \%$ $74.7 \% \quad 10.4 \%$ $47.9 \% \quad 13.1 \%$
}

1 Scas|Scas656.13d

2 Kwal|Kwal47.18002

3 Scer|YLR053C

4 Sbay|sbayc 672 consensus $/ 100 \%$ consensus $/ 90 \%$ consensus $/ 80 \%$ consensus/ $70 \%$

1 Scas|Scas656.13d

2 Kwal|Kwal47.18002

3 Scer|YLR053C

4 Sbay|sbayc672-g32.1 $51.4 \% \quad 12.1 \%$ consensus $100 \%$

consensus $/ 90 \%$

consensus $/ 80 \%$ consensus/70\%

cov pid $100.0 \% 100.0 \%$ $74.7 \% \quad 10.4 \%$ $47.9 \% \quad 13.1 \%$ $51.4 \% \quad 12.1 \%$ $100.0 \% \quad 100.0 \%$ $74.7 \% \quad 10.4 \%$ $47.9 \% \quad 13.1 \%$ 1[ MMVFAHTDEIQDP -

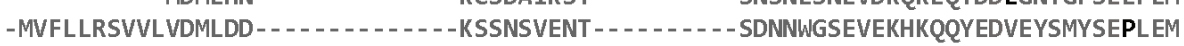

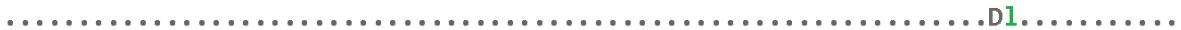

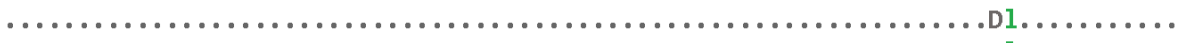

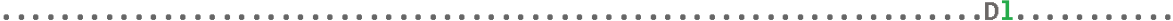
............h.s...........pspsulcph.........sss.htsEl.t.c.ph-DLt..h.oE.hph

81 LNEESR- - - - - - EVSSNTTQHATPEYERIEEEL TNLHNL FGIEPDG-TSKRQPKQTRKKSKSNPFYRTPEKVKEYLNRK -REDSNF SFDEELELPVCEL- -RELEFEQKAGVETKERQHEQIEGRSRSICSLARPRLPMRKSNPFYFPSRHIKNMISKH ESQDNNDSIEDFLFFNINLT - -QEVEFENQRQY - - - - - - - - - - - EHTKKTKKHNPFYVPSEVVREMVKKH EPQDDNENMEDCWYFSMDVG- -QELEFERQ⿻NQE- - - - - - - - - - GNTTKAKKYNPFYVPSKVVREMVSKA ..p-sp........hs.s.h..tp.EaEp.tt..................t.ph.hpK.NPFYhsschl+phlp+t ..p-sp.......hs.s.h..tp.EaEp.tt.................t.ph.hpK.NPFYhsschltphlp+t ..p-sp.......hs.s.h..tp.EaEp.tt.................t.ph.hpK.NPFYhsschl+phlp+t .spDsN.sh--.h.hshshs..pElEFEppp.................... cpTpKt+KPNPFYhPSchV+EMlsK+

cov pid 161 KSRS KSRSTSDALRSLNHNVINNRTKDTENWTK ISNEKSRT - - -PEDSIDQDIDRHS TNQRKRKNTHK

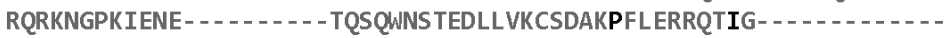
ALNGRI- - - GVEWQSIA--KS- - - -

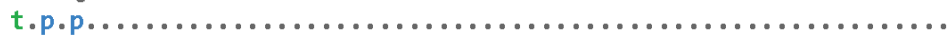

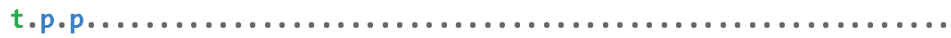

t.p.p...............................................

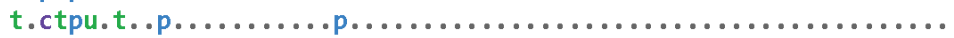




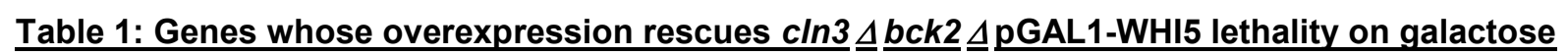

\section{Systematic name}

Genes identified in 3/3 screens

YAL039C

YAL040C

YDR133C

YEL004W

YLR053C

YLR294C

YMR199W

YOR099W

YOR202W

YOR209C

YOR250C

YPL082C

Genes identified in 2/3 screens

YBL062W

YBL067C

YBL071C

YCL018W

YCL055W

YCR060W

YDR359C

YGR029W

YHR023W

YHR035W

YHR039C-A

YJL007C

YJL220W

YJR091C

YLR245C

YMR125W

YMR290W-A

YNL250W

YNR011C

YOR285W

YPL035C

YPL142C

Genes identified in 1/3 screen

YAL045C

YAR007C

YBL006C

YBL044W

YBL051C

YBR235W

YBR278W

YCL022C

YCR003W

YCR073C

YCR085W

YDL068W

YDL215C

YDR162C

\section{Standard name Gene function (SGD)}

CYC3
CLN3
YDR133C
YEA4
YLR053C/NSR1
YLR294C
CLN1
KTR1
HIS3
NPT1
CLP1
MOT1

YBL062W

UBP13

YBL071C

LEU2

KAR4

TAH1

EAF1

ERV1

MYO1

NEL1

VMA10

YJL007C

YJL220W

JSN1

CDD1

STO1

YMR290W-A

RAD50

PRP2

RDL1

YPL035C

YPL142C
Cytochrome c heme lyase (holocytochrome c synthase); attaches he $\mathrm{G} 1$ cyclin involved in cell cycle progression; activates Cdc28p kinas $\epsilon$ Dubious open reading frame; unlikely to encode a functional protein, Uridine diphosphate-N-acetylglucosamine (UDP-GlcNAc) transporte Putative protein of unknown function

Dubious open reading frame; unlikely to encode a functional protein, G1 cyclin involved in regulation of the cell cycle; activates Cdc28p ki Alpha-1,2-mannosyltransferase; involved in O- and $\mathrm{N}$-linked protein Imidazoleglycerol-phosphate dehydratase; catalyzes the sixth step ir Nicotinate phosphoribosyltransferase; acts in the salvage pathway o Component of the cleavage and polyadenylation factor I (CF I); CF 1 Essential protein involved in regulation of transcription; removes Spt

Dubious open reading frame; unlikely to encode a functional protein, Ubiquitin-specific protease that cleaves Ub-protein fusions; UBP13 r Putative protein of unknown function; conserved among S. cerevisia Beta-isopropylmalate dehydrogenase (IMDH); catalyzes the third st $\epsilon$ Transcription factor required for response to pheromones; also requ Component of conserved R2TP complex (Rvb1-Rvb2-Tah1-Pih1); F Component of the NuA4 histone acetyltransferase complex; acts as Flavin-linked sulfhydryl oxidase of the mitochondrial IMS; N-terminus Type II myosin heavy chain; required for wild-type cytokinesis and ct Activator of Sar1p GTPase activity; paralog of Sec23 but does not a: Subunit $G$ of the V1 peripheral membrane domain of V-ATPase; par Putative protein of unknown function; conserved among $\mathrm{S}$. cerevisia Dubious open reading frame; unlikely to encode a functional protein, Member of the Puf family of RNA-binding proteins; interacts with $\mathrm{mF}$ Cytidine deaminase; catalyzes the modification of cytidine to uridine Large subunit of the nuclear mRNA cap-binding protein complex; int Dubious open reading frame; unlikely to encode a functional protein, Subunit of MRX complex with Mre11p and Xrs2p; complex is involv€ RNA-dependent DExD/H-box ATPase; required for activation of splii Thiosulfate sulfurtransferase; contains a rhodanese-like domain; loc Dubious open reading frame; unlikely to encode a functional protein, Dubious open reading frame; unlikely to encode a functional protein,

Dubious open reading frame; unlikely to encode a functional protein, Subunit of heterotrimeric Replication Protein A (RPA); RPA is a high Component of the RSC chromatin remodeling complex; interacts wit Putative protein of unknown function; YBL044W is not an essential $r$ Protein involved in G2/M phase progression and response to DNA d Vacuolar membrane cation-chloride cotransporter (CCC); likely med Third-largest subunit of DNA polymerase II (DNA polymerase epsilo Dubious open reading frame; unlikely to encode a functional protein, Mitochondrial ribosomal protein of the large subunit; protein abundal MAP kinase kinase kinase of HOG1 mitogen-activated signaling pat Putative protein of unknown function; conserved among $\mathrm{S}$. cerevisia Dubious open reading frame; unlikely to encode a functional protein, NAD(+)-dependent glutamate dehydrogenase; degrades glutamate 1 Protein involved in the HOG (high osmolarity glycerol) pathway; neg: 


\begin{tabular}{|c|c|}
\hline YDR310C & SUM1 \\
\hline YDR336W & MRX8 \\
\hline YDR393W & SHE9 \\
\hline YDR407C & TRS120 \\
\hline YDR420W & HKR1 \\
\hline YER010C & YER010C \\
\hline YFR007W & YFH7 \\
\hline YGL041C & YGL041C \\
\hline YGL128C & CWC23 \\
\hline YGL168W & HUR1 \\
\hline YGR037C & ACB1 \\
\hline YGR211W & ZPR1 \\
\hline YGR237C & YGR237C \\
\hline YHR193C & EGD2 \\
\hline YIL039W & TED1 \\
\hline YIL052C & RPL34B \\
\hline YIL110W & HPM1 \\
\hline YJR023C & YJR023C \\
\hline YJR129C & EFM3 \\
\hline YJR151C & DAN4 \\
\hline YKL066W & YKL066W \\
\hline YKL147C & YKL147C \\
\hline YKR012C & YKR012C \\
\hline YKR094C & RPL40B \\
\hline YLL045C & RPL8B \\
\hline YLR044C & PDC1 \\
\hline YLR171W & YLR171W \\
\hline YML094W & GIM5 \\
\hline YML100W-A & YML100W-A \\
\hline YML117W & NAB6 \\
\hline YMR020W & FMS1 \\
\hline YMR094W & CTF13 \\
\hline YMR130W & DPI35 \\
\hline YMR304C-A & YMR304C-A \\
\hline YNL061W & NOP2 \\
\hline YNL115C & YNL115C \\
\hline YNL251C & NRD1 \\
\hline YNL301C & RPL18B \\
\hline YOL013W-A & YOL013W-A \\
\hline YOL139C & CDC33 \\
\hline YOL150C & YOL150C \\
\hline YOL166C & YOL166C \\
\hline YOR075W & UFE1 \\
\hline YOR187W & TUF1 \\
\hline YOR200W & YOR200W \\
\hline YPL239W & YAR1 \\
\hline YPL276W & YPL276W \\
\hline YPR050C & YPR050C \\
\hline YPR112C & MRD1 \\
\hline
\end{tabular}

Transcriptional repressor that regulates middle-sporulation genes; $r \epsilon$ Protein that associates with mitochondrial ribosome; sumoylated unc Protein required for normal mitochondrial morphology; mitochondrial Component of transport protein particle (TRAPP) complex II; TRAPF Mucin family member that functions as an osmosensor in the HOG p Bifunctional HMG aldolase/oxaloacetate decarboxylase; requires div Putative kinase with similarity to the PRK/URK/PANK kinase subfar Dubious open reading frame; unlikely to encode a functional protein, Component of a complex containing Cef1p; putatively involved in pre Protein with a role in DNA repair; mutants show reduced efficiency 0 Acyl-CoA-binding protein; transports newly synthesized acyl-CoA es' Essential protein with two zinc fingers; present in nucleus of growing Putative protein of unknown function; green fluorescent protein (GFF Alpha subunit of the nascent polypeptide-associated complex (NAC) GPI-glycan remodelase; conserved phosphoesterase domain-contai Ribosomal 60S subunit protein L34B; homologous to mammalian rit AdoMet-dependent methyltransferase; involved in a novel 3-methylh Putative protein of unknown function; open reading frame overlaps $\mathrm{L}$ S-adenosylmethionine-dependent methyltransferase; seven-beta-str Cell wall mannoprotein; has similarity to Tir1p, Tir2p, Tir3p, and Tir4 Dubious open reading frame; unlikely to encode a functional protein, Dubious open reading frame; unlikely to encode a functional protein, Dubious open reading frame; unlikely to encode a functional protein, Ubiquitin-ribosomal 605 subunit protein L40B fusion protein; cleavec Ribosomal 60 S subunit protein L8B; required for processing of $27 \mathrm{~S} F$ Major of three pyruvate decarboxylase isozymes; key enzyme in alcr Dubious open reading frame; unlikely to encode a functional protein, Subunit of the heterohexameric cochaperone prefoldin complex; pre Putative protein of unknown function; identified by gene-trapping, mi Putative RNA-binding protein; associates with mRNAs encoding cell Polyamine oxidase; converts spermine to spermidine, which is requi Subunit of the CBF3 complex; F-box protein of the leucine-rich-repe Putative protein of unknown function; YMR130W is not an essential Dubious open reading frame; unlikely to encode a functional protein, rRNA m5C methyltransferase; methylates cytosine at position 2870 Putative protein of unknown function; green fluorescent protein (GFF RNA-binding subunit of Nrd1 complex; complex interacts with exoso Ribosomal 60S subunit protein L18B; homologous to mammalian rik Putative protein of unknown function; identified by SAGE

Translation initiation factor elF4E; mRNA cap binding protein and su Dubious open reading frame; unlikely to encode a functional protein, Dubious open reading frame; unlikely to encode a functional protein, t-SNARE protein required for retrograde vesicular traffic; involved in Mitochondrial translation elongation factor Tu (EF-Tu); involved in fu Dubious open reading frame; unlikely to encode a functional protein, Ankyrin-repeat containing, nucleocytoplasmic shuttling assembly chi $\mathrm{NAD}(+)$-dependent formate dehydrogenase; may protect cells from 1 Dubious open reading frame; unlikely to encode a functional protein, Essential conserved small ribosomal subunit (40s) synthesis factor; 
bioRxiv preprint doi: https://doi.org/10.1101/2020.04.20.033787; this version posted April 20, 2020. The copyright holder for this preprint (which

A was not certified by peer review) is the author/funder. All rights reserved. No reuse allowed without permission.

C

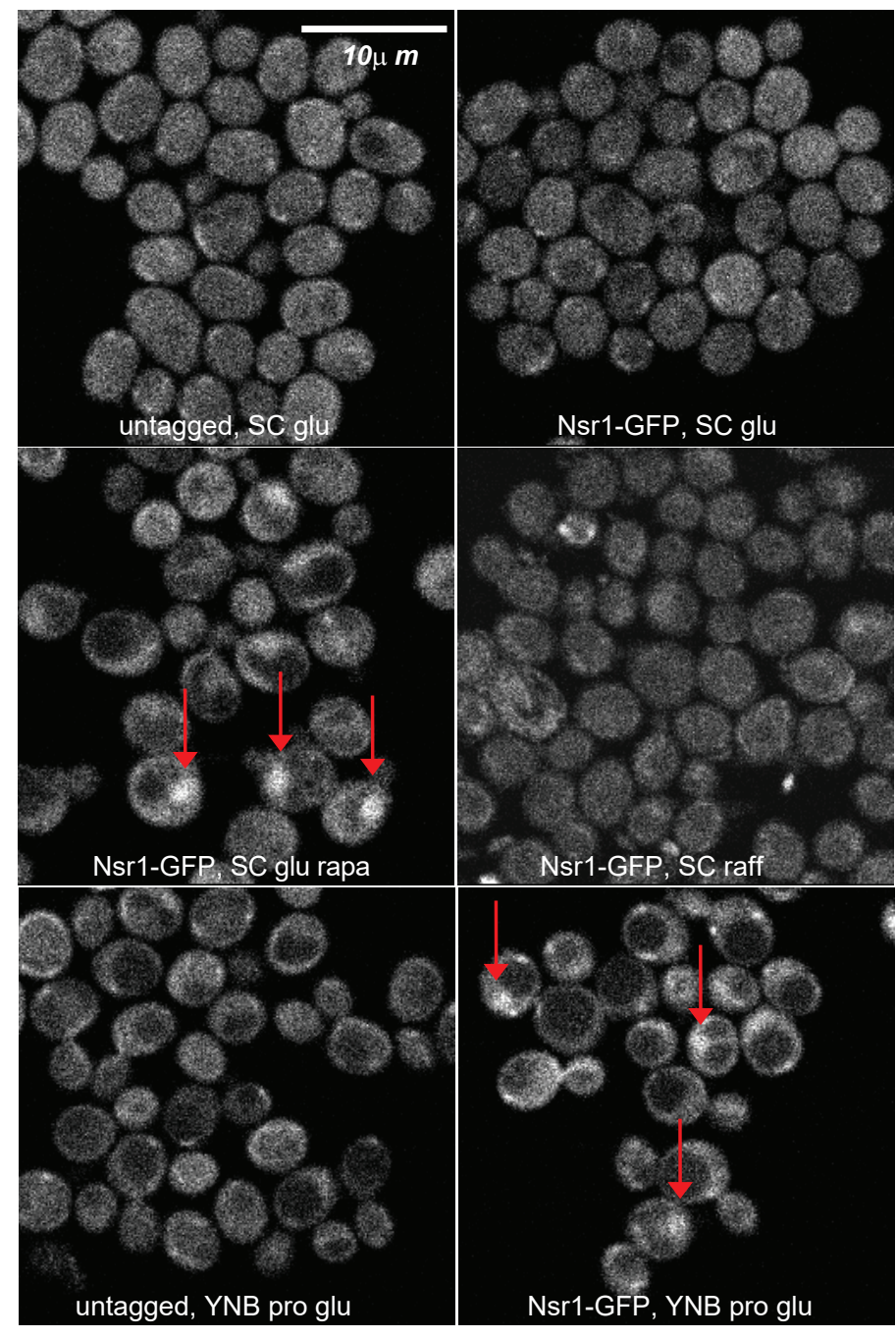

$\mathrm{B}$

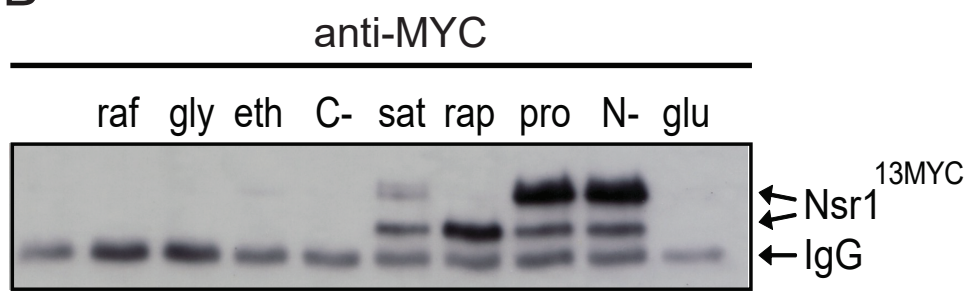

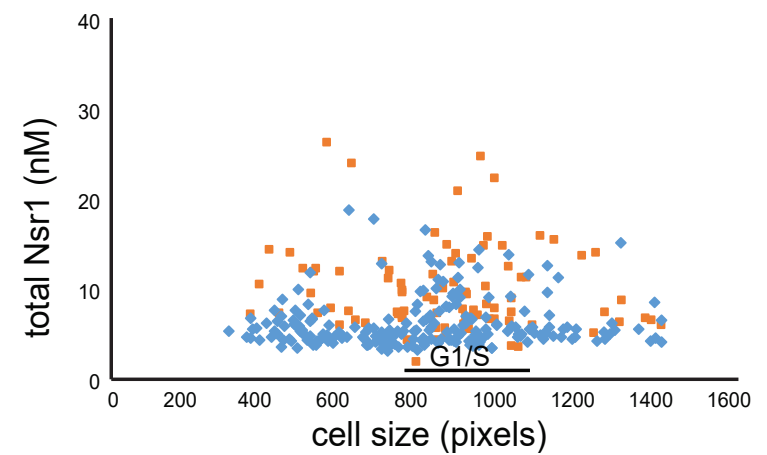

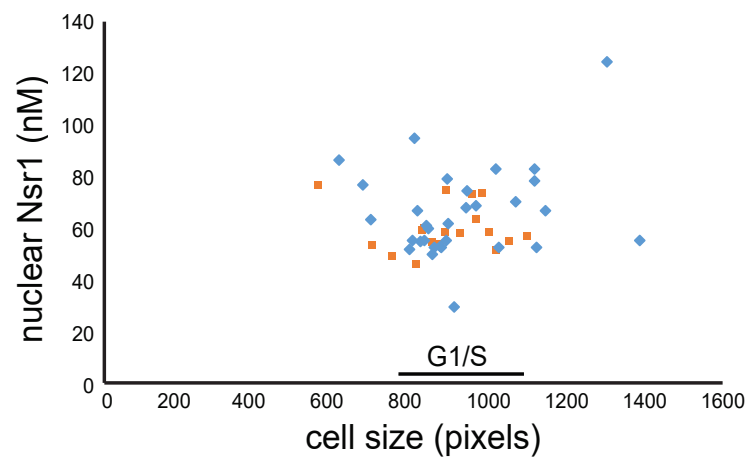

$\mathrm{D}$

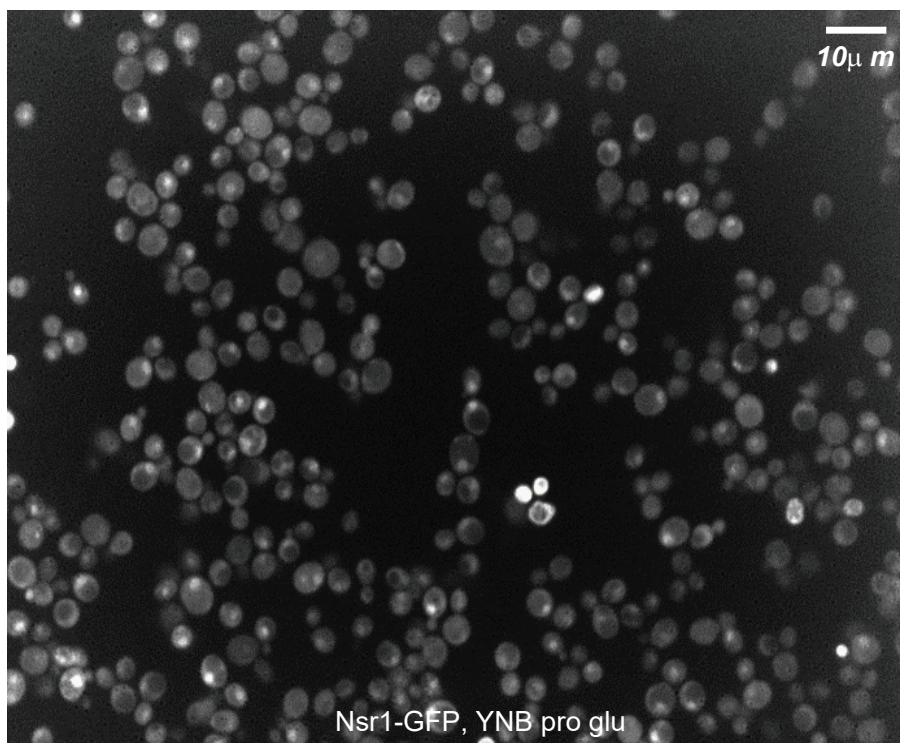


A

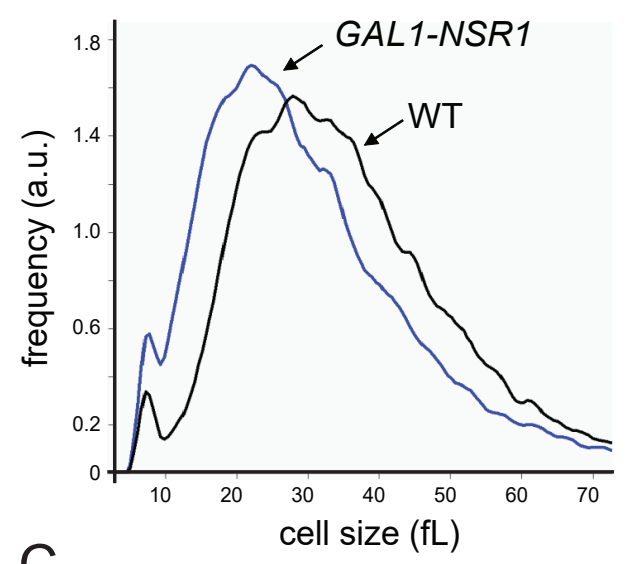

C
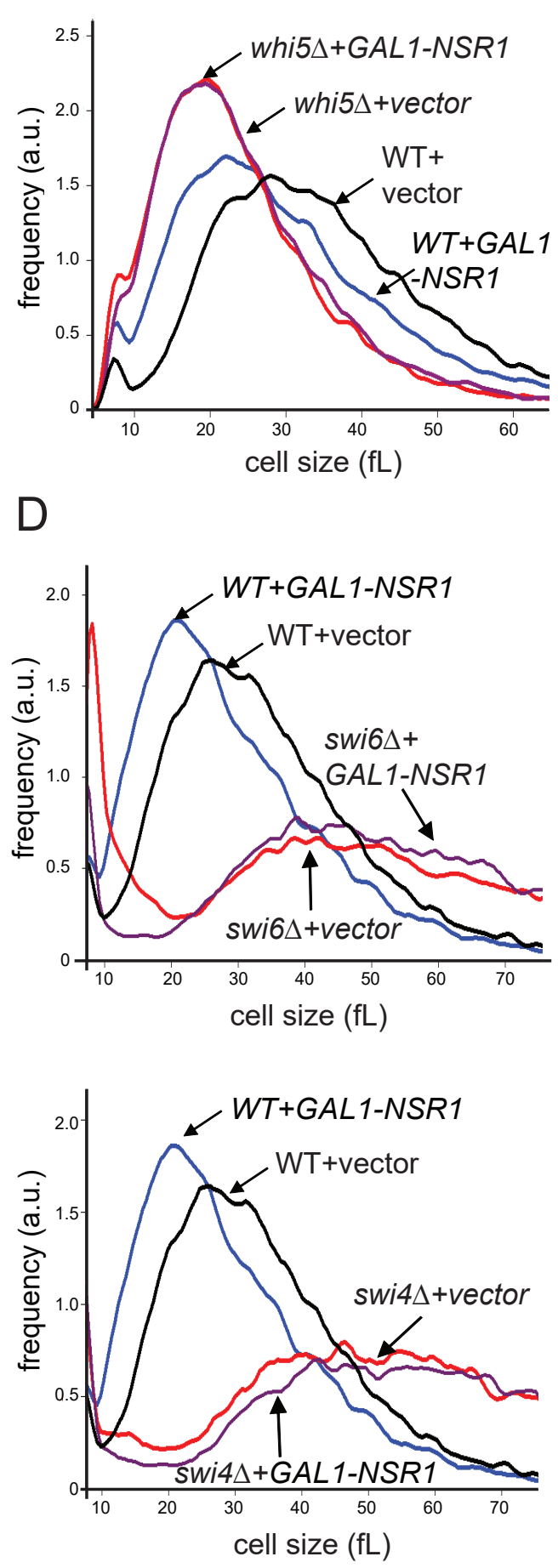
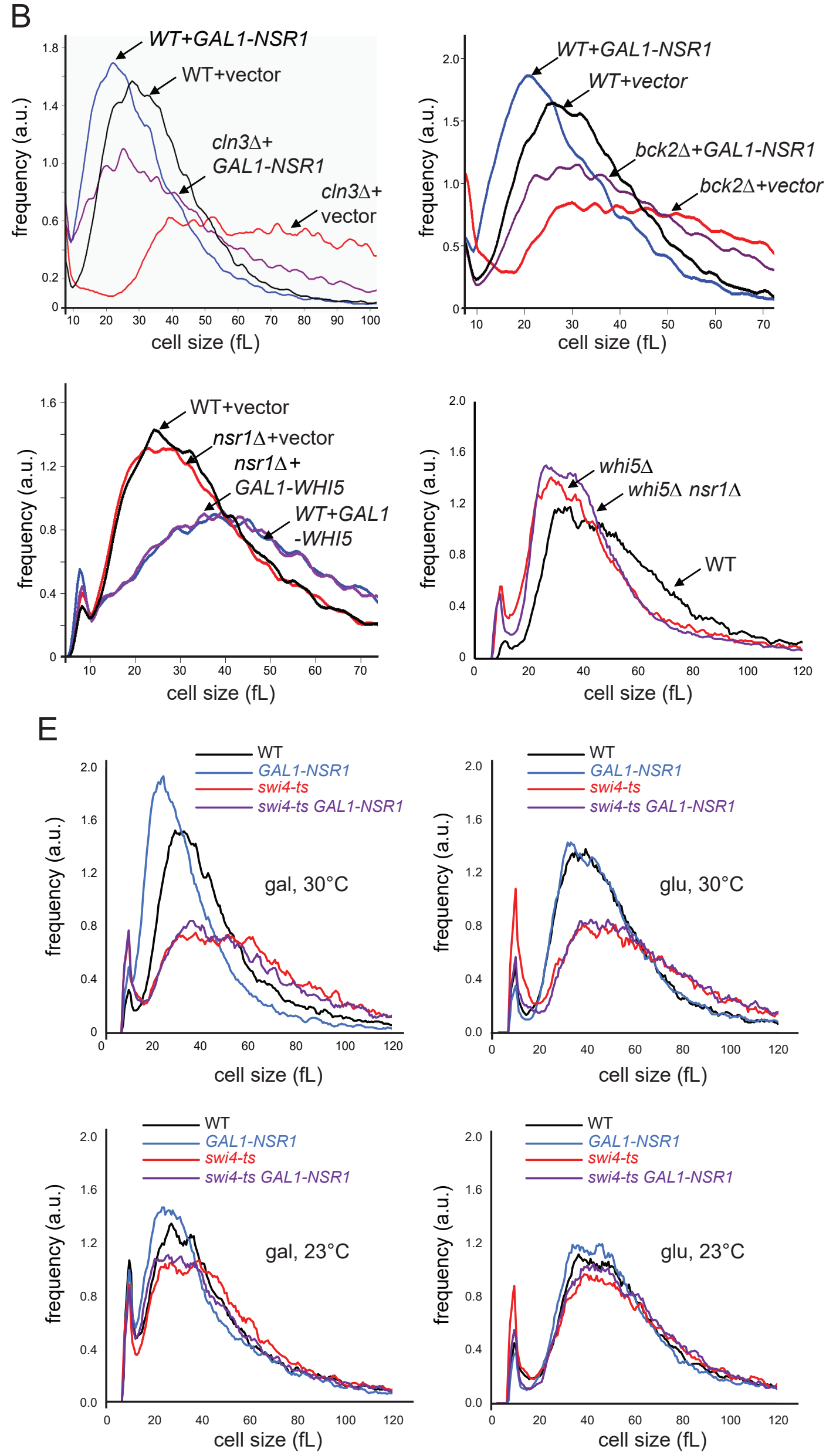

Tollis et al. Figure 3 
bioRxiv preprint doi: https://doi.org/10.1101/2020.04.20.033787; this version posted April 20, 2020. The copyright holder for this preprint (which was not certified by peer review) is the author/funder. All rights reserved. No reuse allowed without permission.

A
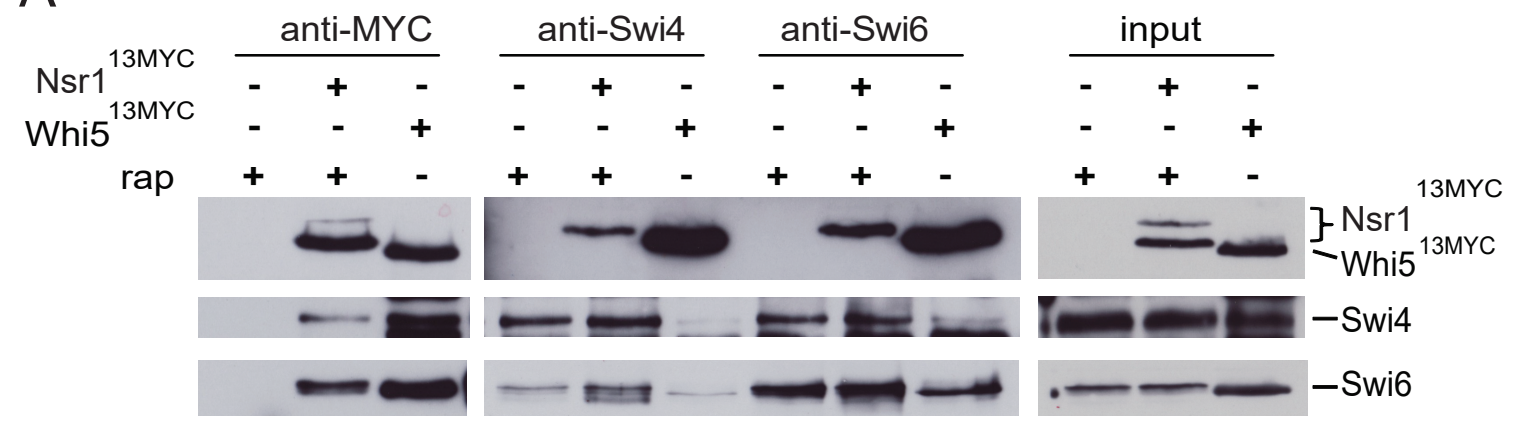

B

SBF (ug)

\begin{tabular}{lllllll}
0.1 & 0 & 0.25 & 0.5 & 1 & & \multicolumn{2}{c}{ GSH resin } \\
& & & Nsr1 & 1
\end{tabular}

anti-Flag

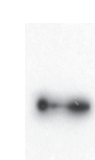

anti-Swi6

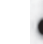

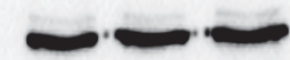

C

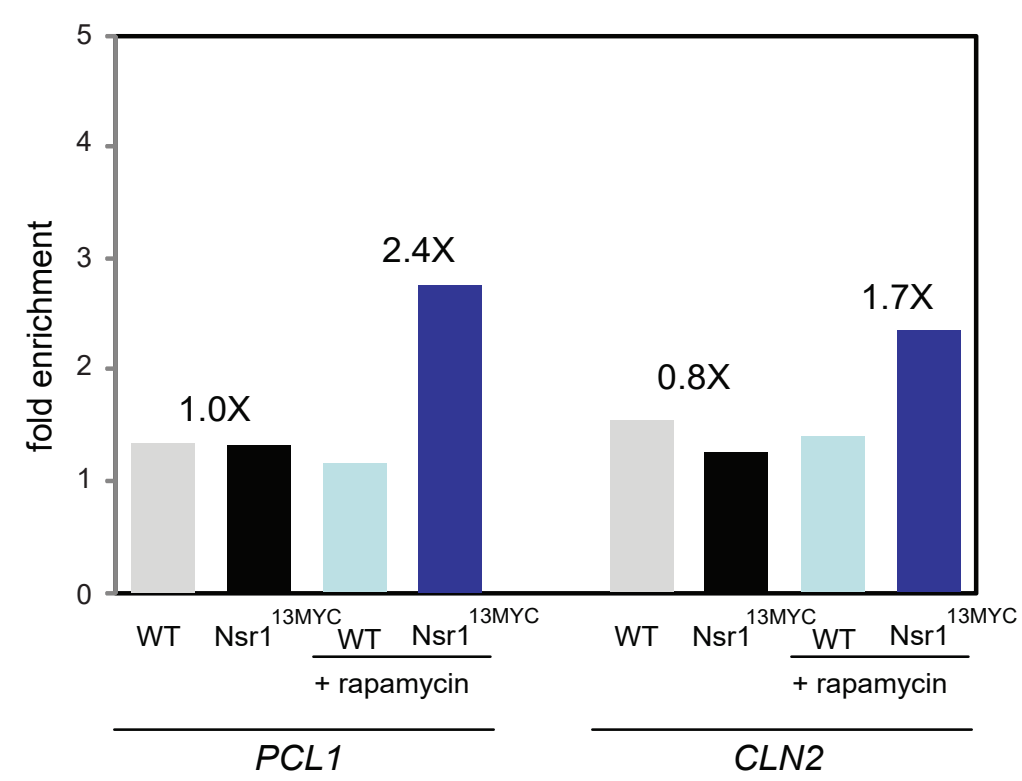

- Swi4

- Swi6
anti-Swi6

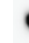
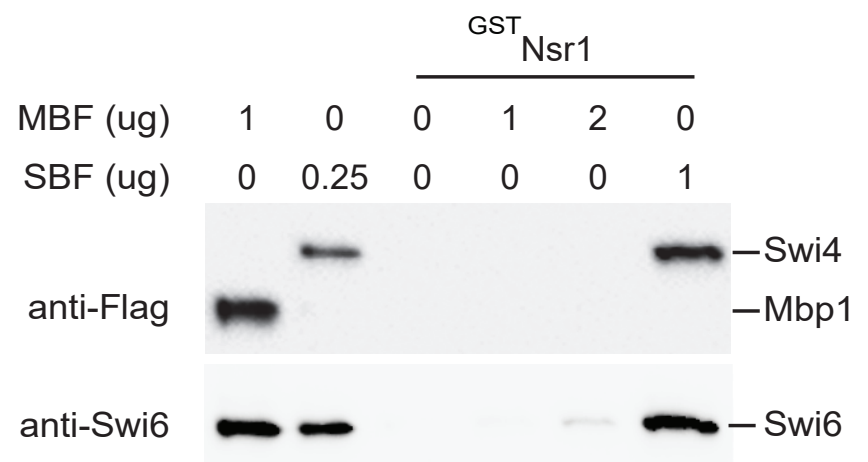

D
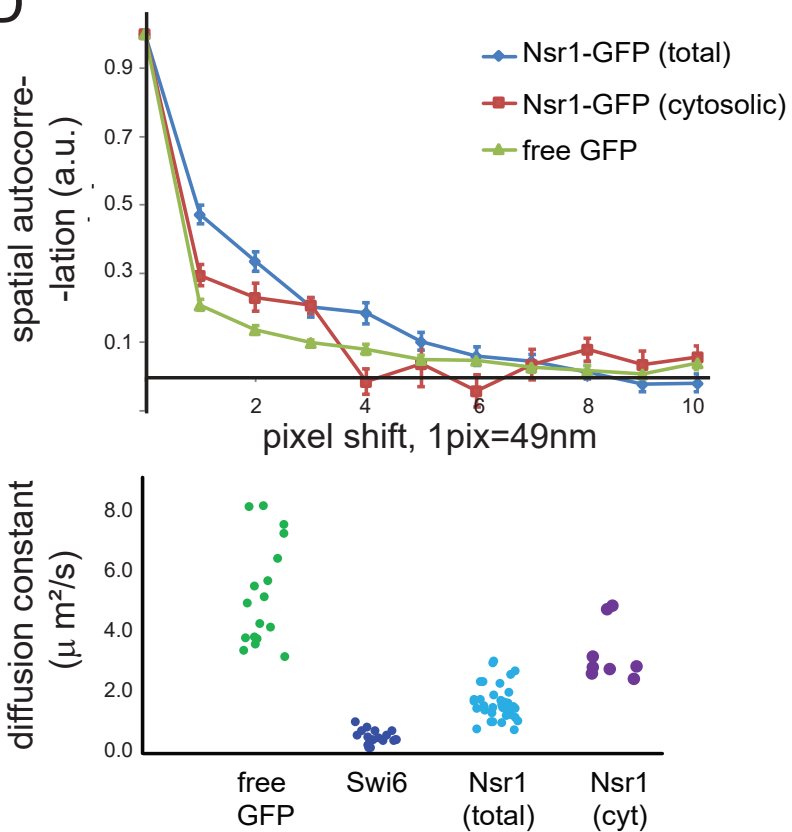
A
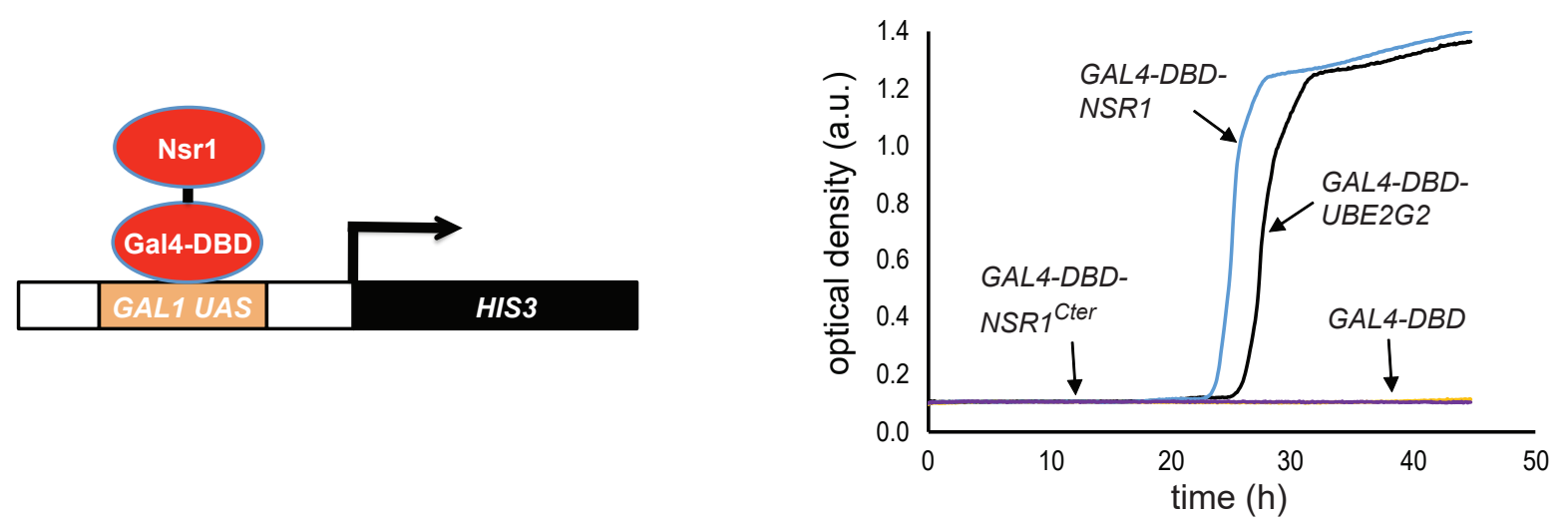

B

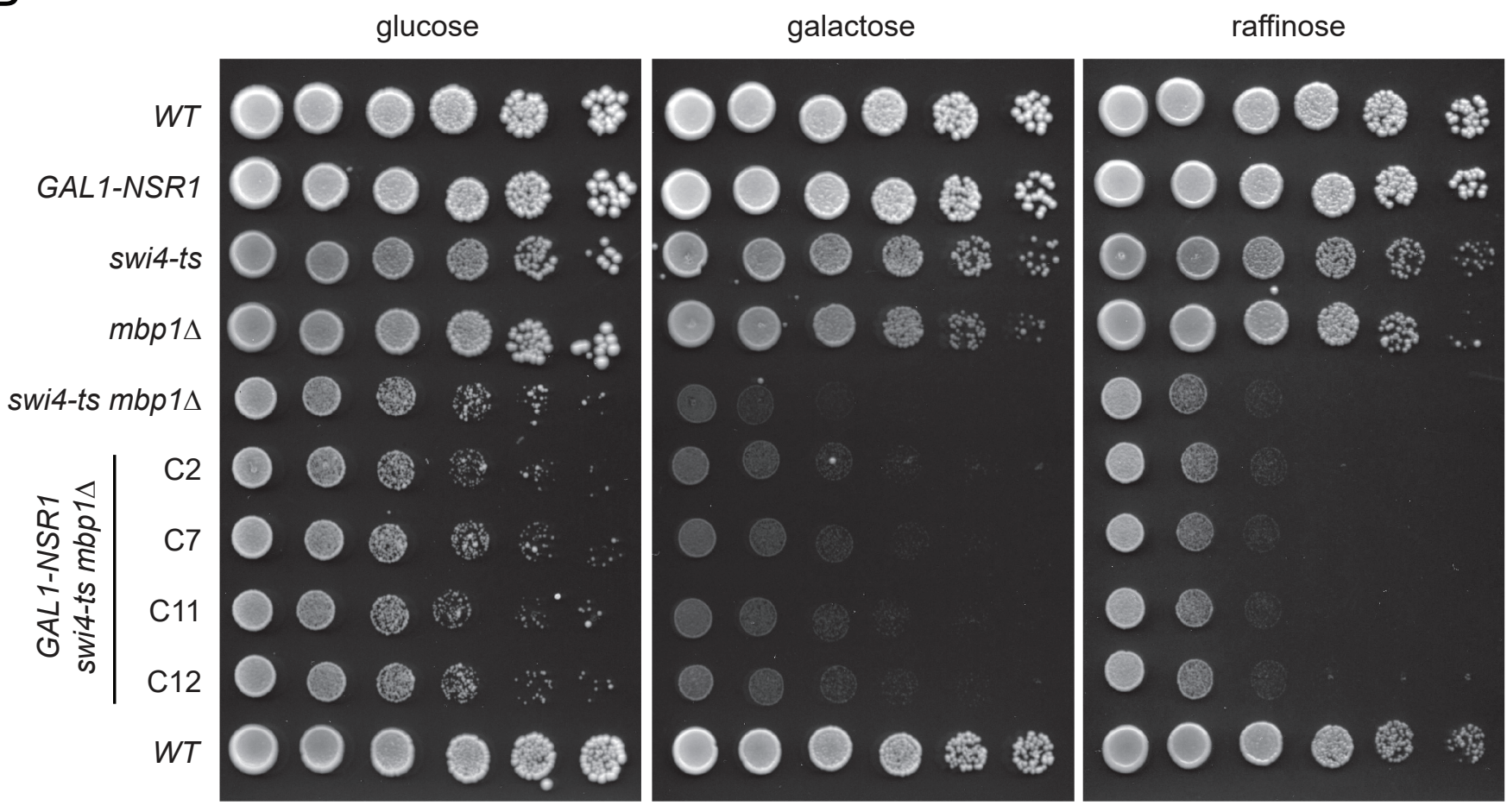

C

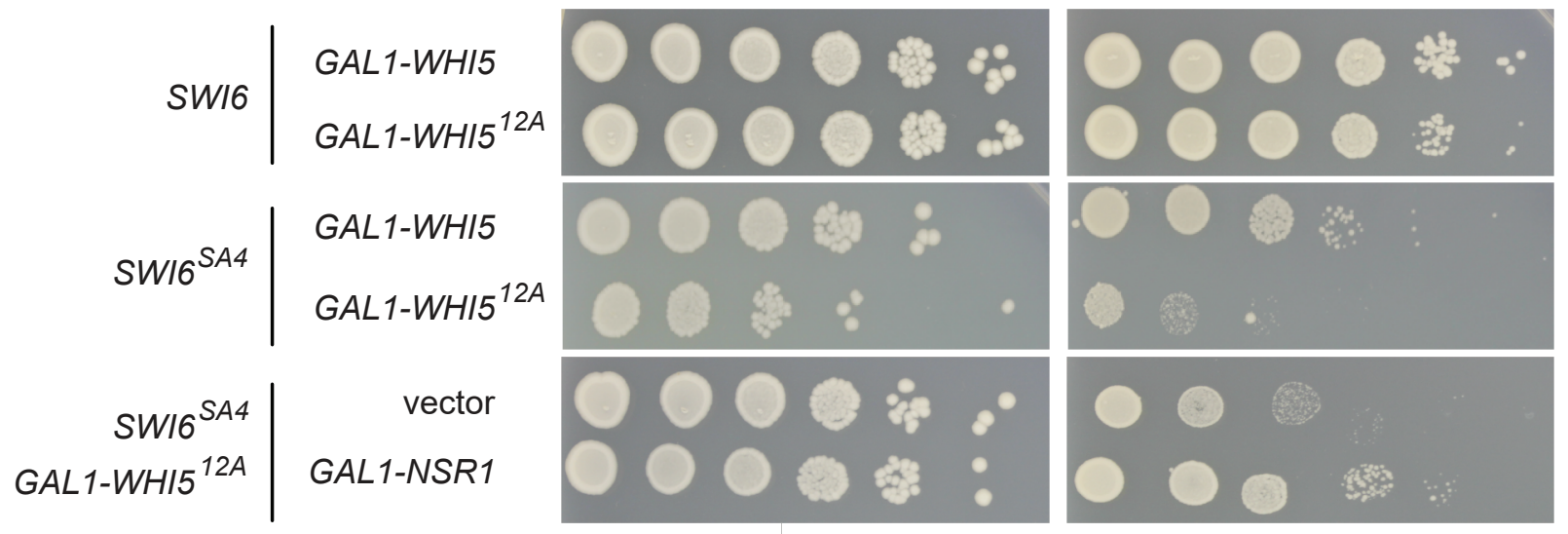


A
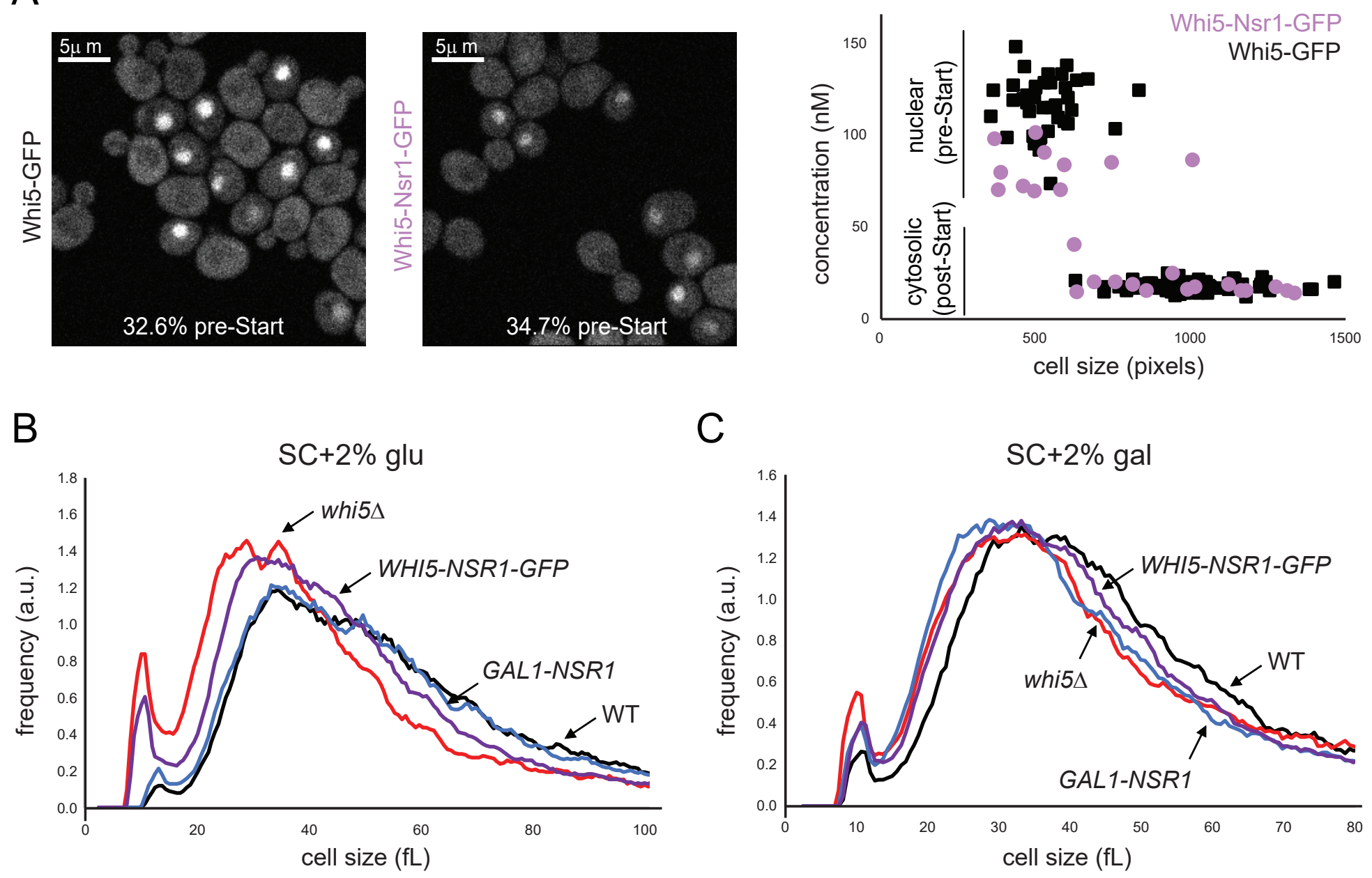

C

D
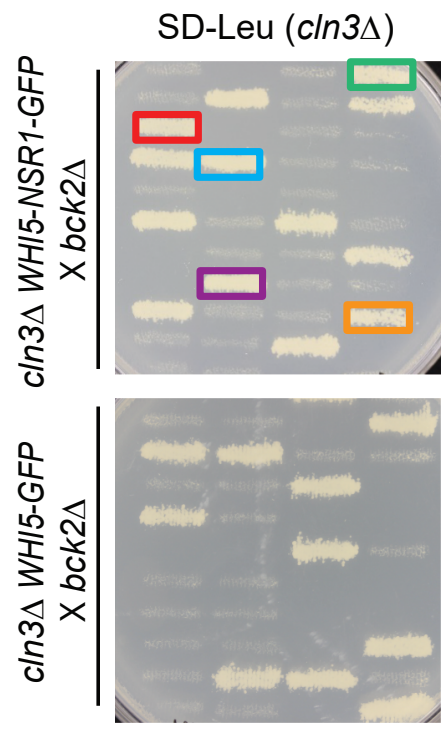

$\mathrm{SD}+\mathrm{Nat}(b c k 2 \Delta)$
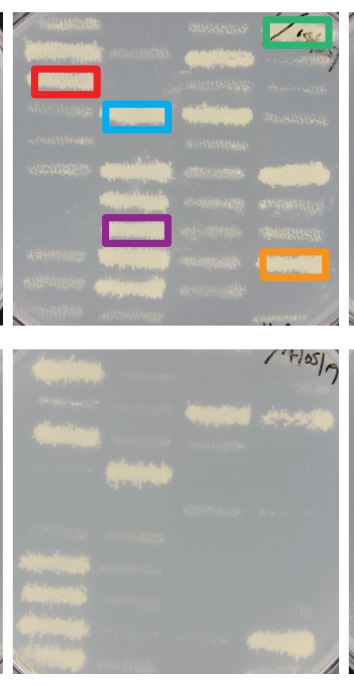

$=$ viable $c \ln 3 \Delta b c k 2 \Delta$ clones

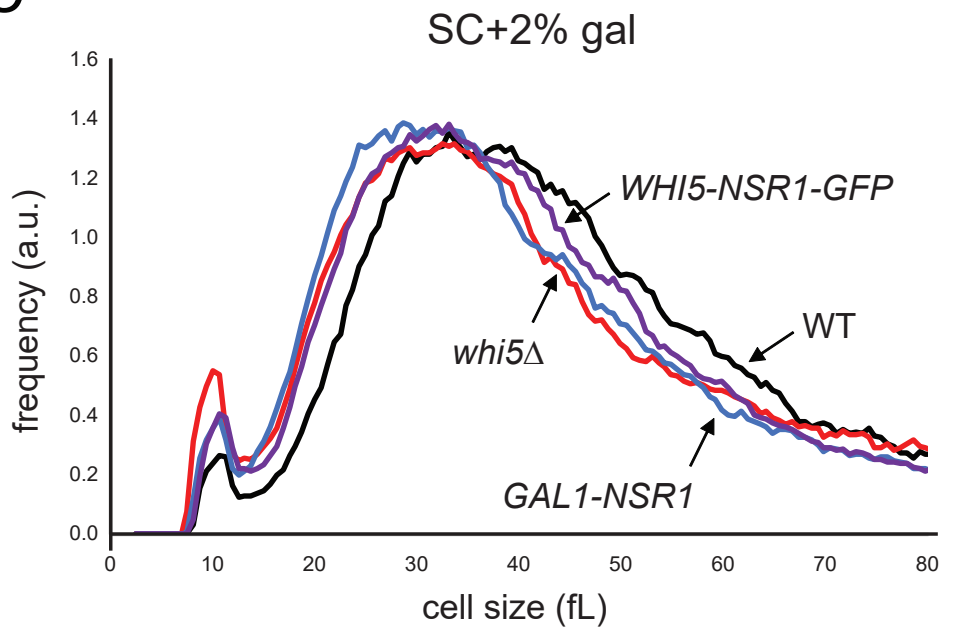

E

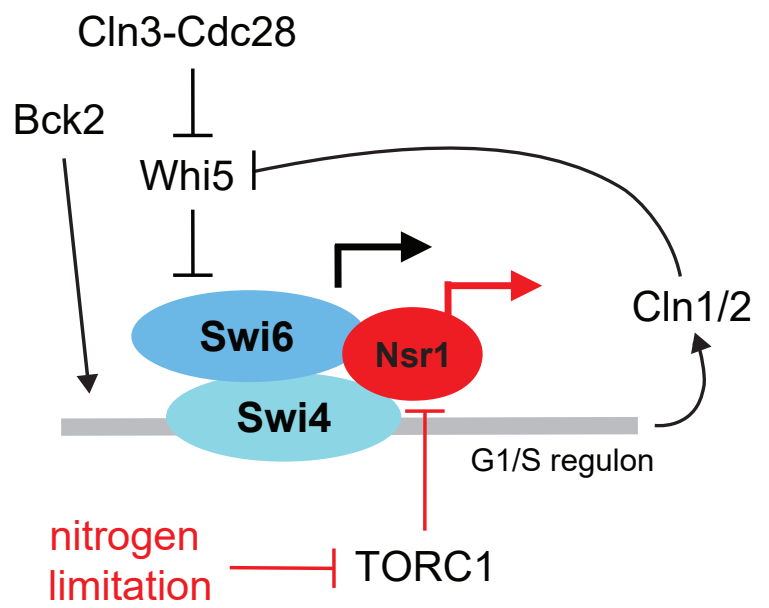




\section{Supplemental Table 1. Yeast strains and plasmids used in this study}

\begin{tabular}{|c|c|c|c|c|}
\hline Strain name & $\begin{array}{l}\text { Strain } \\
\text { number }\end{array}$ & $\begin{array}{l}\text { Relevant } \\
\text { genotype }\end{array}$ & MAT & Source \\
\hline Wild-type (WT) haploid & yMT1448 & his3 $\Delta 1$ leu2 $\Delta 0$ met $15 \Delta 0$ ura3 $\Delta 0$ & a & Winzeler et al. 1999 \\
\hline WT diploid & уМт1450 & $\begin{array}{l}\text { his3 } \Delta 1 / \text { his3 } \Delta 1 \text { leu2 } \Delta O / \text { leu2 } \Delta O \text { ura3 } \Delta O / \text { ura3 } \Delta O \\
\text { MET15/met15 } \Delta O L Y S 2 / \text { lys } 2 \Delta O\end{array}$ & $a / \alpha$ & C. Roberts \\
\hline WHI5/whi5 4 diploid, clone 1 & yMT5036 & WHI5/whi5::kanMX & $a / \alpha$ & This work \\
\hline WHI5/whi5 4 diploid, clone 2 & yMT5037 & WHI5/whi5::kanMX & $a / \alpha$ & This work \\
\hline WHI5/whi5 $\Delta$ diploid, clone 3 & yMT5038 & WHI5/whi5::kanMX & $a / \alpha$ & This work \\
\hline$c \ln 3 \Delta b c k 2 \Delta G A L 1-W H I 5$ & yMT4317 & $\begin{array}{l}\text { cln3::LEU2, bck2::natMX whi5::kanMX-pGAL1-WHI5, } \\
\text { mfa1::MFA1pr-spHIS5+, can1A }\end{array}$ & $\alpha$ & This work \\
\hline Nsr1-GFP & yMT5039 & nsr1:: NSR1-mGFPmut3-HIS3MX & $a$ & This work \\
\hline Nsr1 $1^{13 M Y C}$ & yMT4321 & nsr1:: NSR1-13MYC-kanMX & $a$ & This work \\
\hline Nsr1-WT GFP & уМт5040 & nsr1::NSR1-GFP-natMX & - & This work \\
\hline$n s r 1 \Delta$ & BY2664 & nsr1::kanMX & a & Giaver et al. 2002 \\
\hline sch9as & yMT4237 & sch9::sch9as-natMX & $\alpha$ & Jorgensen et al. 2004 \\
\hline sch9as nsr14 & yMT5041 & sch9::sch9as-natMX nsr1::kanMX & $\alpha$ & This work \\
\hline GAL1-NSR1 & yMT4323 & Iys2 $\triangle O$ nsr1::kanMX-pGAL1-NSR1 & a & This work \\
\hline $\operatorname{cln} 3 \Delta$ & yМт2125 & cln3::LEU2 & a & Jorgensen et al. 2002 \\
\hline$b c k 2 \Delta$ & BY6163 & bck2::kanMX & a & Giaver et al. 2002 \\
\hline swi64 & BY4131 & swi6::kanMX & a & Giaver et al. 2002 \\
\hline swi4t & BY6109 & swi4:: kanMX & a & Giaver et al. 2002 \\
\hline swi4-ts & yMT5044 & 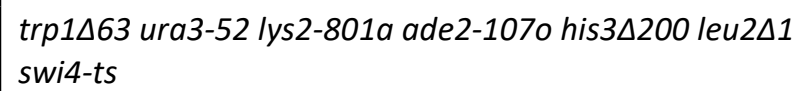 & $\alpha$ & B. Andrews \\
\hline swi4-ts GAL1-NSR1 & уМт5047 & 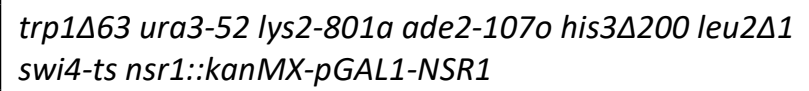 & $\alpha$ & This work \\
\hline whi5s & уМТ3249 & whi5::kanMX & a & Costanzo et al. 2004 \\
\hline whi5 $\Delta$ nsr1s & yMT5042 & whi5::kanMX nsr1::natMX & - & This work \\
\hline Whi5-GFP & уМT5009 & whi5::WHI5-mGFPmut3-HIS3MX & a & $\begin{array}{l}\text { Dorsey Tollis et al. } \\
2018\end{array}$ \\
\hline GAL1-NSR1 Whi5-GFP & yMT5043 & whi5::WHI5-mGFPmut3-HIS3MX kanMX-pGAL1-NSR1 & - & This work \\
\hline Swi6-GFP & yMT5006 & Swi6::SWI6-mGFPmut3-HIS3MX & a & $\begin{array}{l}\text { Dorsey Tollis et al. } \\
2018\end{array}$ \\
\hline Whis $5^{13 M Y c}$ & yMT3248 & whi5:: WHI5-13MYC-kanMX & a & Costanzo et al. 2004 \\
\hline Whi5 $5^{\text {HA }}$ & yMT4325 & whi5:: WHI5-3HA-kanMX & a & This work \\
\hline GAL1-NSR1 Whi5 $5^{\mathrm{HA}}$ & yМT4320 & nsr1::kanMX-pGAL1-NSR1, whi5:: WHI5-3HA-HIS3MX & - & This work \\
\hline Bait strain & AH109 & $\begin{array}{l}\text { trp10901, leu2-3, 112, ura3-52, his3-200, gal44, } \\
\text { gal804, lys2::GAL1 UAs-GAL1TATA-HIS3, GAL2 UAS-GAL2TATA- } \\
\text { ADE2, ura3::MEL1 UAs-MEL1TATA-IacZ }\end{array}$ & a & $\begin{array}{l}\text { Clontech, James et } \\
\text { al. } 1996\end{array}$ \\
\hline $\begin{array}{l}\text { WT (Figs } 5 \text { and S5, bottom } \\
\text { line) }\end{array}$ & & $\begin{array}{l}\operatorname{trp} 1 \Delta 63 \text { Gal2 + ura3-52 lys2-801a ade2-107o his } 3 \Delta 200 \\
\text { leu2 } \Delta 1\end{array}$ & $\alpha$ & B. Andrews \\
\hline mbp14 & уМT5046 & $\begin{array}{l}\text { trp1 } \triangle 63 \text { Gal2+ ura3-52 lys2-801a ade2-107o his } 3 \Delta 200 \\
\text { leu2 } 21 \text { mbp1::TRP1 }\end{array}$ & $\alpha$ & B. Andrews \\
\hline
\end{tabular}




\begin{tabular}{|c|c|c|c|c|}
\hline Strain name & $\begin{array}{l}\text { Strain } \\
\text { number }\end{array}$ & $\begin{array}{l}\text { Relevant } \\
\text { genotype }\end{array}$ & MAT & Source \\
\hline swi4-ts mbp1A & yMT5045 & 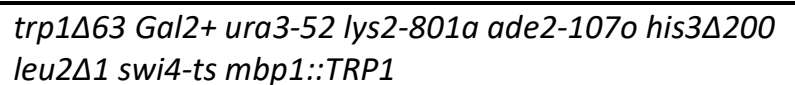 & $\alpha$ & B. Andrews \\
\hline $\begin{array}{l}\text { GAL1-NSR1 swi4-ts } \\
\text { mbp1 } 1 \text { clone C2 }\end{array}$ & yMT5048 & 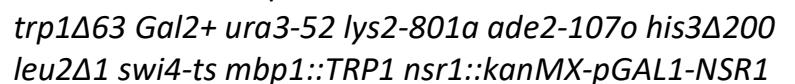 & $\alpha$ & This work \\
\hline $\begin{array}{l}\text { GAL1-NSR1 swi4-ts } \\
\text { mbp1 } 1 \text { clone } C 7\end{array}$ & yMT5049 & 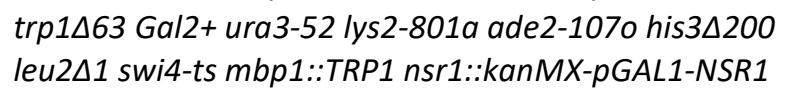 & $\alpha$ & This work \\
\hline $\begin{array}{l}\text { GAL1-NSR1 swi4-ts } \\
\text { mbp1A clone C11 }\end{array}$ & yMT5050 & 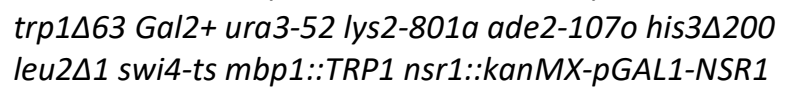 & $\alpha$ & This work \\
\hline $\begin{array}{l}\text { GAL1-NSR1 swi4-ts } \\
\text { mbp1A clone C12 }\end{array}$ & yMT5051 & 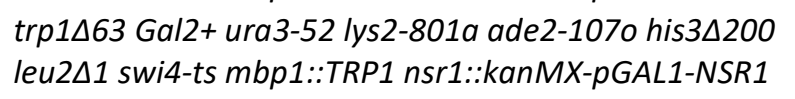 & $\alpha$ & This work \\
\hline Whi5-Nsr1-GFP & yMT5053 & whi5::WHI5-NSR1-mGFPmut3-HIS3MX & $a$ & This work \\
\hline$b c k 2 \Delta$ & уMT2299 & bck2::natMx & $\alpha$ & This work \\
\hline cln3A WHI5-NSR1-GFP & yMT5055 & cln3::LEU2 whi5::WHI5-NSR1-mGFPmut3-HIS3MX & a & This work \\
\hline $\begin{array}{l}\text { cln } 3 \Delta \text { bck } 2 \Delta \text { WHI5-NSR1-GFP } \\
\text { clone } 1\end{array}$ & yMT5057 & $\begin{array}{l}\text { cln3::LEU2 bck2::natMX whi5::WHI5-NSR1-mGFPmut3- } \\
\text { HIS3MX }\end{array}$ & - & This work \\
\hline $\begin{array}{l}\text { cln3 } 4 b c k 2 \Delta \text { WHI5-NSR1-GFP } \\
\text { clone } 2\end{array}$ & yMT5058 & $\begin{array}{l}\text { cln3::LEU2 bck2::natMX whi5::WHI5-NSR1-mGFPmut3- } \\
\text { HIS3MX }\end{array}$ & - & This work \\
\hline $\begin{array}{l}\text { cln } 3 \Delta \text { bck } 2 \Delta \text { WHI5-NSR1-GFP } \\
\text { clone } 3\end{array}$ & yMT5059 & $\begin{array}{l}\text { cln3::LEU2 bck2::natMX whi5::WHI5-NSR1-mGFPmut3- } \\
\text { HIS3MX }\end{array}$ & - & This work \\
\hline $\begin{array}{l}\text { cln3 } 3 \text { bck2 } \triangle \text { WHI5-NSR1-GFP } \\
\text { clone } 4\end{array}$ & уМт5060 & $\begin{array}{l}\text { cln3::LEU2 bck2::natMX whi5::WHI5-NSR1-mGFPmut3- } \\
\text { HIS3MX }\end{array}$ & - & This work \\
\hline $\begin{array}{l}\text { cln3 } 3 \text { bck2 } 2 \text { WHI5-NSR1-GFP } \\
\text { clone } 5\end{array}$ & yMT5061 & $\begin{array}{l}\text { cln3::LEU2 bck2::natMX whi5::WHI5-NSR1-mGFPmut3- } \\
\text { HIS3MX }\end{array}$ & - & This work \\
\hline Plasmid name & $\begin{array}{l}\text { Plasmid } \\
\text { number }\end{array}$ & Description & & Source \\
\hline pVenus & pMT4642 & $\begin{array}{l}\text { yEpVenus_URA: URA3 } 2 \mu \text { plasmid, TDH3-promoter- } \\
\text { driven expression of Venus (YFP) }\end{array}$ & & $\begin{array}{l}\text { E. Bilsland, Bilsland } \\
\text { et al. } 2013\end{array}$ \\
\hline pmCherry & pMT4643 & $\begin{array}{l}\text { yEpGAP-Cherry: URA3 } 2 \mu \text { plasmid, TDH3-promoter- } \\
\text { driven expression of yEmRFP }\end{array}$ & & $\begin{array}{l}\text { N. Dean, Keppler- } \\
\text { Ross et al. } 2008\end{array}$ \\
\hline pGAL1-NSR1 & pMT4644 & $\begin{array}{l}\text { pGAL1-NSR1-HA URA3 CEN plasmid built in the } \\
\text { pMT4177 backbone }\end{array}$ & & This work \\
\hline pGAL1-WHI5 & рMT3445 & pGAL1-WHI5 HIS3 CEN & & Costanzo et al. 2004 \\
\hline pGAL4DBD & pMT4645 & pGBKT7 cloning vector TRP $2 \mu$ & & Clontech \\
\hline pGAL4DBD-UBE2G2 & pMT4646 & pGBKT7-UBE2G2 & & This work \\
\hline pGAL4DBD-NSR1 & pMT4647 & pGBKT7-NSR1 & & This work \\
\hline pGAL4DBD-Cter(NSR1) & pMT4648 & pGBKT7-NSR1 $1^{83-99}$ & & This work \\
\hline pGAL1-Whi5 $5^{12 A}$ & рМT3455 & pGAL1-WHI5 $12 \mathrm{~A}$ HIS3 CEN & & Costanzo et al. 2004 \\
\hline pGAL1-SWI6 & pBD1756 & SWI6 $6^{\text {SAA }}$ LEU2 $2 \mu$ plasmid, derived from pBD176 & & Sidorova et al. 1995 \\
\hline
\end{tabular}

* All strains are congenic with yMT1448 (S288C background) unless otherwise indicated. 